\title{
The mitochondrial outer membrane protein SYNJ2BP interacts with the cell adhesion molecule TMIGD1 and can recruit it to mitochondria
}

Christian Hartmann ${ }^{1,2}$, Ysabel Alessa Schwietzer ${ }^{1,2}$, Daniel Kummer ${ }^{1,2,3}$, Nils Kirschnick ${ }^{1,2}$, Esther Hoppe ${ }^{1,2}$, Eva-Maria Thüring ${ }^{1,2}$, Mark Glaesner-Ebnet ${ }^{1,2}$, Frauke Brinkmann ${ }^{1,2}$, Volker Gerke 2 , Stefan Reuter ${ }^{4}$, Masanori Nakayama ${ }^{5}$ and Klaus Ebnet ${ }^{1,2,3,6^{*}}$

\begin{abstract}
Background: Transmembrane and immunoglobulin domain-containing protein 1 (TMIGD1) is a recently identified cell adhesion molecule which is predominantly expressed by epithelial cells of the intestine and the kidney. Its expression is downregulated in both colon and renal cancer suggesting a tumor suppressive activity. The function of TMIGD1 at the cellular level is largely unclear. Published work suggests a protective role of TMIGD1 during oxidative stress in kidney epithelial cells, but the underlying molecular mechanisms are unknown.

Results: In this study, we address the subcellular localization of TMIGD1 in renal epithelial cells and identify a cytoplasmic scaffold protein as interaction partner of TMIGD1. We find that TMIGD1 localizes to different compartments in renal epithelial cells and that this localization is regulated by cell confluency. Whereas it localizes to mitochondria in subconfluent cells it is localized at cell-cell contacts in confluent cells. We find that cell-cell contact localization is regulated by $\mathrm{N}$-glycosylation and that both the extracellular and the cytoplasmic domain contribute to this localization. We identify Synaptojanin 2-binding protein (SYNJ2BP), a PDZ domain-containing cytoplasmic protein, which localizes to both mitochondria and the plasma membrane, as interaction partner of TMIGD1. The interaction of TMIGD1 and SYNJ2BP is mediated by the PDZ domain of SYNJ2BP and the C-terminal PDZ domain-binding motif of TMIGD1. We also find that SYNJ2BP can actively recruit TMIGD1 to mitochondria providing a potential mechanism for the localization of TMIGD1 at mitochondria.
\end{abstract}

Conclusions: This study describes TMIGD1 as an adhesion receptor that can localize to both mitochondria and cellcell junctions in renal epithelial cells. It identifies SYNJ2BP as an interaction partner of TMIGD1 providing a potential mechanism underlying the localization of TMIGD1 at mitochondria. The study thus lays the basis for a better understanding of the molecular function of TMIGD1 during oxidative stress regulation.

Keywords: Adhesion molecule, Cell-cell adhesion, JAM, Kidney epithelium, SYNJ2BP, TMIGD1

\footnotetext{
*Correspondence: ebnetk@uni-muenster.de

"Institute-Associated Research Group "Cell adhesion and cell polarity",

University of Münster, Von-Esmarch-Str. 56, 48149 Münster, Germany

${ }^{2}$ Institute of Medical Biochemistry, ZMBE, University of Münster,

Von-Esmarch-Str. 56, 48149 Münster, Germany

Full list of author information is available at the end of the article
}

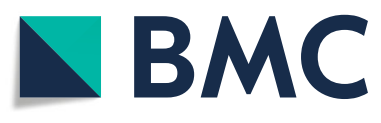

(c) The Author(s). 2020 Open Access This article is licensed under a Creative Commons Attribution 4.0 International License, which permits use, sharing, adaptation, distribution and reproduction in any medium or format, as long as you give appropriate credit to the original author(s) and the source, provide a link to the Creative Commons licence, and indicate if changes were made. The images or other third party material in this article are included in the article's Creative Commons licence, unless indicated otherwise in a credit line to the material. If material is not included in the article's Creative Commons licence and your intended use is not permitted by statutory regulation or exceeds the permitted use, you will need to obtain permission directly from the copyright holder. To view a copy of this licence, visit http://creativecommons.org/licenses/by/4.0/ The Creative Commons Public Domain Dedication waiver (http://creativecommons.org/publicdomain/zero/1.0/) applies to the data made available in this article, unless otherwise stated in a credit line to the data. 


\section{Background}

Epithelial cells and endothelial cells are connected by cell adhesion receptors localized at intercellular junctions. These adhesion receptors are not only required to mediate physical cell cohesion but also to transmit signals and to mediate intercellular communication. The genes encoding cell adhesion receptors have been subjected to multiplication and diversification during evolution resulting in large families of cell-cell adhesion receptors, including the cadherin and the immunoglobulin superfamilies $[1,2]$. The generation of large cell adhesion receptor superfamilies has been the basis of multicellularity and the development of higher organisms.

In most cases, cell-cell adhesion receptors interact with cytoplasmic adaptor proteins which either link the receptors to the cytoskeleton or to intracellular signalling pathways. The association with adaptor proteins is frequently mediated by sequence motifs like proline-rich motifs, FERM domain-binding motifs or PDZ domainbinding motifs, which interact with specific domains present in the adaptor proteins, such as $\mathrm{SH} 3$ domains, FERM domains or PDZ domains, respectively [3]. The promiscuous nature of many of the motif - domain interactions has further contributed to the pleiotropic functions of cell-cell adhesion receptors $[4,5]$.

Transmembrane and immunoglobulin domain-containing protein 1 (TMIGD1) is a member of the Ig-superfamily (IgSF) with similarity to the Junctional Adhesion Molecule (JAM) subfamily [6]. TMIGD1 contains two Ig-like domains of the C2-type, a single transmembrane region, and a short cytoplasmic domain of 21 amino acids (AA) that terminates in a canonical type I PDZ domain-binding motif [7]. It is expressed predominantly in the intestine and the kidney (https://www.proteinatlas.org/ENSG00000182271-TMIGD1/ ) [8]. Its expression is downregulated in tumours derived from intestine and kidney [8-11] as well as in inflamed intestinal tissues $[12,13]$, suggesting a tumour-suppressive function and a protective role during inflammation.

The function of TMIGD1 at the cellular level is largely unknown. Downregulation of TMIGD1 by RNA interference in cultured epithelial cells increases the cell's susceptibility to oxidative stress, and its ectopic expression has a protective effect [14]. Also, reduced expression levels of TMIGD1 correlate with increased tissue damage after oxidative stress induced by ischemia and reperfusion in mice [14]. These findings suggest a protective role of TMIGD1 during oxidative stress, perhaps by influencing the metabolism of mitochondria which play a central role in the generation of reactive oxygen species [15]. The molecular mechanism through which TMIGD1 exerts its functions are completely unknown.

In this study, we identify Synaptojanin-2-binding protein (SYNJ2BP) as cytoplasmic binding partner of TMIGD1. SYNJ2BP has been described as a dual- location protein which localizes to the outer membrane of mitochondria $[16,17]$ as well as to the plasma membrane [18-20]. Our findings identify a cytoplasmic binding partner of TMIGD1 and provide the first mechanistic insights into the function of TMIGD1 in kidney epithelial cells.

\section{Results \\ TMIGD1 is transported from the cytoplasm to the cell surface after deletion of the $\mathrm{D} 1 \mathrm{Ig}$ domain}

Given the high similarity of TMIGD1 to members of the Junctional Adhesion Molecule (JAM) family [6], and its predominant expression by kidney-derived epithelial cells $[8,14]$, we aimed to characterize the subcellular localization of TMIGD1 in kidney epithelial cells. To this, we expressed TMIGD1 constructs in MDCKII cells, a canine kidney epithelial cell line derived from distal kidney tubules [21]. Stable MDCKII-TetOFF cell lines were generated which allow the expression of either wildtype TMIGD1 (TMIGD1/WT) or TMIGD1 lacking the PDZ domain-binding motif (TMIGD1/A5) under a doxycycline-regulated promoter, as described previously for JAM-A [22]. Since studies with other JAM family members indicated a critical role for the membranedistal Ig-like domain for their enrichment at cell-cell contacts [23], we also generated cell lines expressing a TMIGD1 construct lacking the membrane-distal Ig-like domain $(\triangle \mathrm{D} 1-\mathrm{TMIGD} 1)$ as well as a TMIGD1 construct that lacks both the membrane-distal Ig-like domain and the PDZ domain-binding motif ( $\Delta$ D1-TMIGD1/ $\Delta 5)$ (Fig. 1a). All constructs were expressed at similar levels after removal of doxycycline from the culture medium, as analyzed by Western blotting (Fig. 1b). Surprisingly, both TMIGD1/WT and TMIGD1/ $\Delta 5$ were not detectable at the cell surface when analyzed by flow cytometry, whereas both $\triangle \mathrm{D} 1$-TMIGD1 constructs were localized at the cell surface (Fig. 1b). Immunofluorescence stainings confirmed an exclusive localization of TMIGD1/ WT and TMIGD1/ $\Delta 5$ in cytoplasmic compartments and a localization of $\Delta \mathrm{D} 1$-TMIGD1 and $\Delta \mathrm{D} 1-\mathrm{TMIGD} 1 / \Delta 5$ both in cytoplasmic compartments and at cell-cell junctions (Fig. 1d). These observations thus suggested that the D1 Ig-like domain of TMIGD1 prevents its transport to the cell surface in MDCKII cells. Quantification of cell-cell contacts positive for $\triangle \mathrm{D} 1$-TMIGD1 and $\triangle \mathrm{D} 1$ TMIGD1/ $\Delta 5$ indicated that the number of $\Delta D 1$ TMIGD1/ $\Delta 5$-positive contacts was significantly lower than the number of $\Delta D 1$-TMIGD1-positive contacts (Fig. 1e), strongly suggesting that a PDZ domainmediated interaction is required for the stable localization of this construct at cell-cell junctions.

To further address the contribution of the extracellular and the cytoplasmic domain of TMIGD1 to its cell-cell contact localization, we performed localization studies 
A

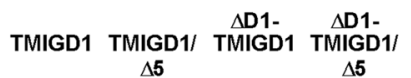

$\overbrace{\mathrm{PDZ}}^{\text {Flag }} \mathrm{J}_{\mathrm{PDZ}}^{\text {Flag }} \overbrace{\mathrm{Flag}}^{\text {Flag }}$

B

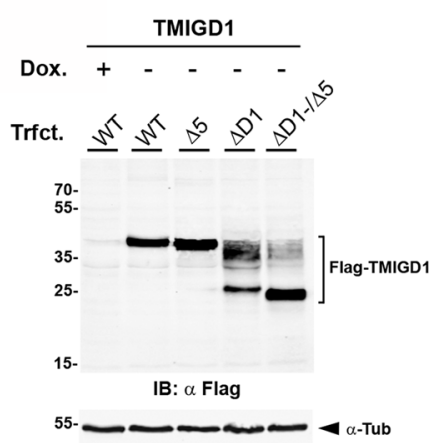

D
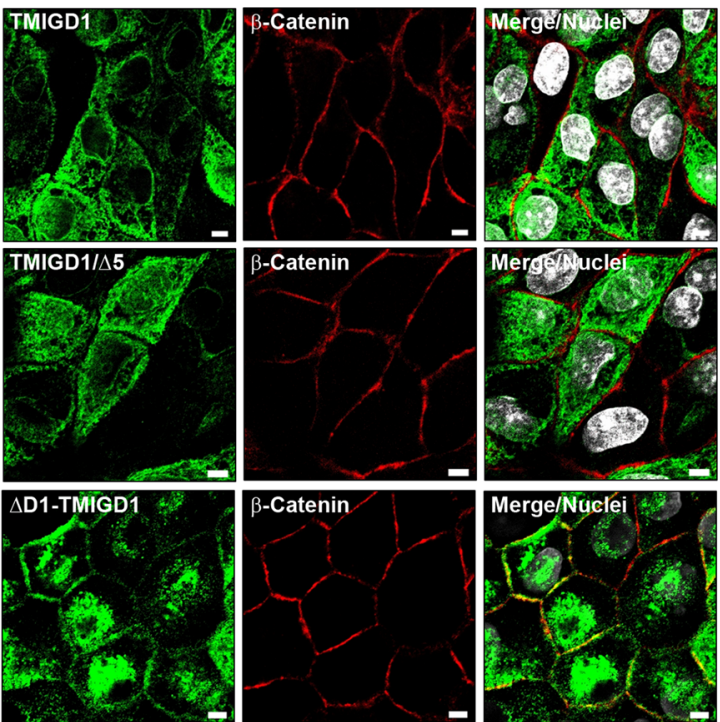

$\triangle \mathrm{D} 1-\mathrm{TM} / \mathrm{CP} 1 / \Delta 5$
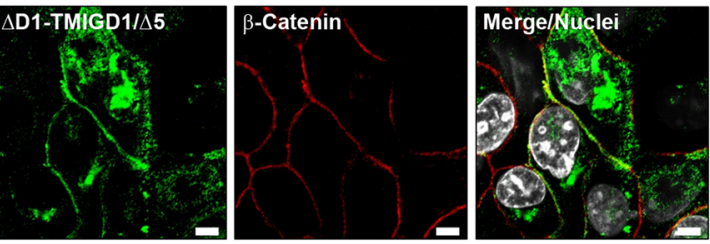

C
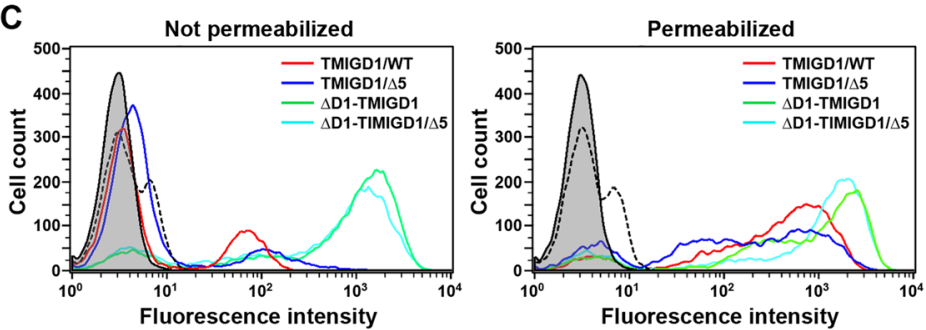

E

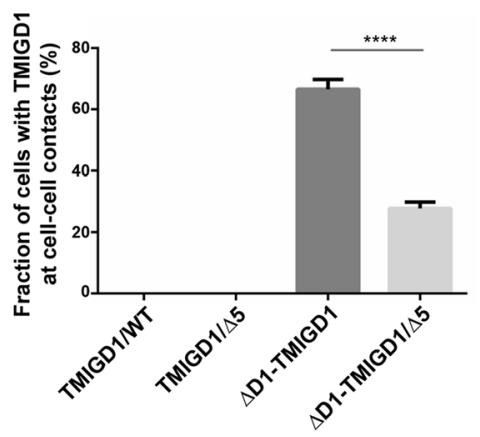

$\mathbf{F}$
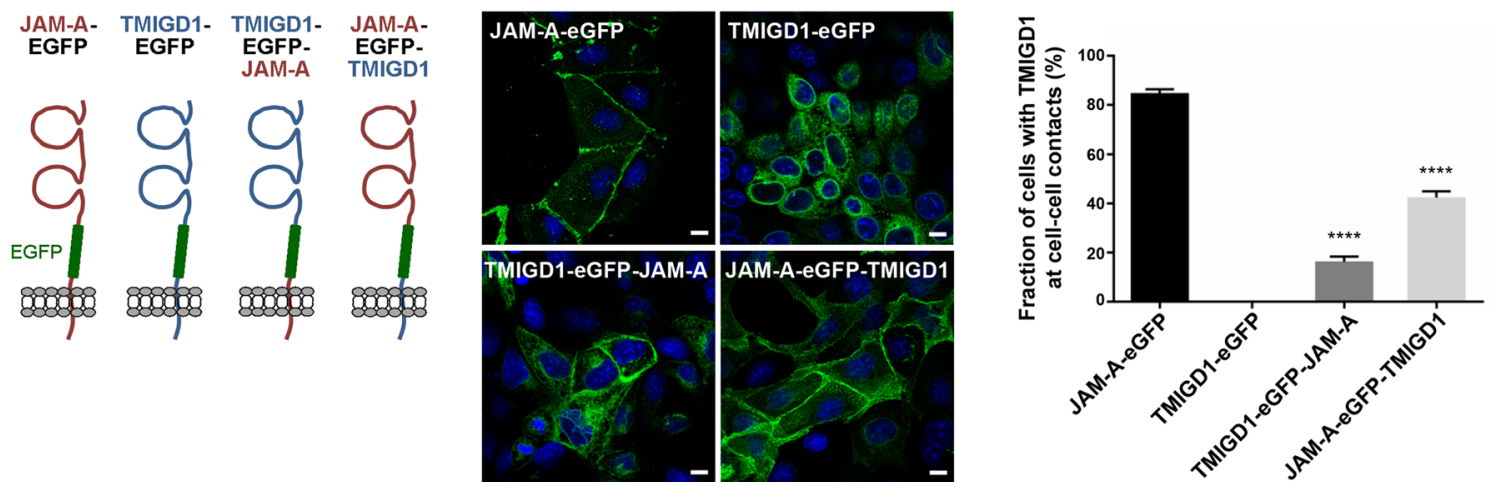

Fig. 1 (See legend on next page.) 
(See figure on previous page.)

Fig. 1 Ectopic TMIGD1 is localized in the cytoplasm of MDCKII cells but is efficiently transported to the cell surface after deletion of its D1 domain. a Schematic presentation of Flag-tagged TMIGD1 constructs expressed in MDCKII-TetOFF cells. The two $\Delta \mathrm{D} 1$ mutants lack the membrane-distal Ig-like domain (D1 domain). The PDZ domain-binding motif (shown in red) is absent in the " $\Delta 5$ " mutants. b MDCKIl cell lines stably transfected with the TMIGD1 constructs depicted in (a) (TMIGD1/WT (WT), TMIGD1/ $\Delta 5(\Delta 5), \Delta D 1-T M I G D 1(\Delta D 1), \Delta D 1-T M I G D 1 / \Delta 5$ ( $\Delta D 1$ $-/ \Delta 5)$ were induced by doxycycline removal to express the transgenes and analyzed by Western blotting with antibodies against the Flag tag. $\mathbf{C}$ Flag-TMIGD1-expressing MDCKII-TetOFF cells were analyzed for cell surface localization of TMIGD1 constructs by flow cytometry using antibodies against the Flag tag. Cells were left untreated (Not permeabilized) to analyze cell surface proteins only, or were permeabilized by saponin treatment (Permeabilized) to analyze total protein levels. Note that the constructs with a complete extracellular domain (TMIGD1/WT, TMIGD1/ $\Delta 5$ ) are predominantly localized in the cytoplasm, whereas constructs lacking the membrane-distal lg-like domain $(\Delta \mathrm{D} 1-\mathrm{TMIGD1}, \Delta \mathrm{D} 1-\mathrm{TMIGD} / \mathrm{\Delta}$ ) are localized at the cell surface. Filled grey lines indicate unstained cells, dotted black lines indicate cells stained with secondary antibodies alone. d Immunofluorescence analysis of TMIGD1-expressing MDCKIl cell lines depicted in panel (a). Cells were stained with antibodies against the Flag tag and against $\beta$-catenin. Nuclei were stained with DAPI (pseudocoloured in white). Note that the constructs lacking the D1 lg-like domain are localized at cell-cell contacts. Scale bars: 5 um. e Quantification of cell-cell contact localization of TMIGD1 constructs. Cells were visually inspected for Flag signals at cell-cell contacts. TMIGD1 signals were rated as cell-cell contact-localized when a clear overlap with $\beta$-catenin signals at linear cell-cell contact sites was observed. Statistical analysis was performed using unpaired Student's t-test. Data were obtained from three independent experiments and are presented as arithmetic means $\pm \mathrm{SEM}$; ${ }^{* * *} P<0.0001$. The differences in cell-cell contact localization between the two $\Delta D 1-T M I G D 1$ constructs $(\triangle D 1-T M I G D 1, \Delta D 1-T M I G D 1 / \Delta 5)$ and each of the two constructs with entire extracellular domains (TMIGD1, TMIGD1/ $\Delta 5)$ are highly significant ( $P<0.0001$; not indicated by asterisks in the graph). $\mathbf{f}$ Cell-cell contact localization of TMIGD1 - JAM-A domainswapping mutants. Left panel: Schematic presentation of domain swapping mutants. Middle panel: TMIGD1 - JAM-A swapping mutants shown in the left panel were transiently expressed in MDCKII cells. The subcellular localization was analyzed by fluorescence microscopy based on the EGFP signals. Right panel: Quantification of cell-cell contact localization of the TMIGD1 - JAM-A domain-swapping mutants. Cells were visually inspected for the localization of EGFP fluorescence signals at linear cell-cell contacts defined by $\beta$-catenin-positive signals (not shown). Statistical analyses were performed using unpaired Student's t-test and display comparisons of the TMIGD1 swapping mutants with the TMIGD1 full length protein (TMIGD1-EGFP). Data were obtained from three independent experiments and are presented as arithmetic means \pm SEM; ${ }^{* * *} P<0.001$

using TMIGD1 - JAM-A swapping mutants. JAM-A has an overall organization similar to TMIGD1 with two Iglike domains, a single transmembrane spanning region and a short cytoplasmic domain, but in contrast to TMIGD1, JAM-A is constitutively localized at cell-cell contacts when expressed in MDCK cells [22]. In one construct we replaced the transmembrane and cytoplasmic domains of TMIGD1 (TMIGD1 - EGFP - JAM-A), in the second construct we replaced the extracellular domain of TMIGD1 (JAM-A - EGFP - TMIGD1) (Fig. 1f, schematics). The TMIGD1 control construct (TMIGD1 - EGFP - TMIGD1) did not localize to cell-cell contacts (Fig. 1f), as observed for the Flag-tagged TMIGD1 constructs (Fig. 1c, d). Replacing the transmembrane and cytoplasmic regions slightly increased the fraction of cell contact-localized TMIGD1 constructs to approximately $20 \%$ of transfected cells (Fig. 1f). Replacing the extracellular domain of TMIGD1 increased the fraction of cell contact-localized TMIGD1 constructs to approximately $40 \%$ of transfected cells (Fig. 1f). These findings suggest that both the extracellular and the transmembrane/cytoplasmic regions of TMIGD1 contribute to its retention in the cytoplasm. Retention in the cytoplasm may be regulated by glycosylation of the extracellular domain as well as by interaction of the cytoplasmic domain with scaffolding proteins, as shown for the glutamate transporter GLAST [24].
TMIGD1 is localized at cell-cell junctions and in the cytoplasm of kidney epithelial cells and is preferentially expressed by epithelial cells of proximal tubules

Besides the small intestine, TMIGD1 is predominantly expressed by epithelial cells in the kidney $[8,9]$. Immunohistochemistry of kidney sections revealed a localization of TMIGD1 both at cell-cell contacts and in cytoplasmic compartments of renal tubular epithelial cells but a complete absence of TMIGD1 expression in glomerular podocytes (Fig. 2a, b). These observations are in line with previous findings showing expression of TMIGD1 in kidney tubules [14]. Co-stainings of TMIGD1 with PHA-E, a marker for proximal kidney tubules [25], indicated that TMIGD1 is predominantly expressed by epithelial cells in proximal tubules (Fig. 2c). Together, these observations show that TMIGD1 is differently expressed by epithelial cells in different kidney compartments with a complete absence in glomerular podocytes. They also suggest that the subcellular localization of TMIGD1 might be different in epithelial cells derived from these different compartments, such as proximal and distal kidney tubules, which could provide a possible explanation of the exclusive localization of ectopically expressed TMIGD1 in the cytoplasm of MDCK cells (Fig. 1c, d), which are derived from distal kidney tubules [21]. 
A
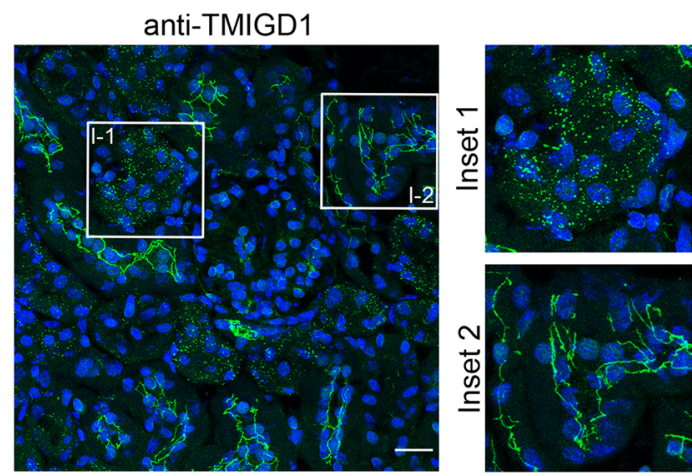

C

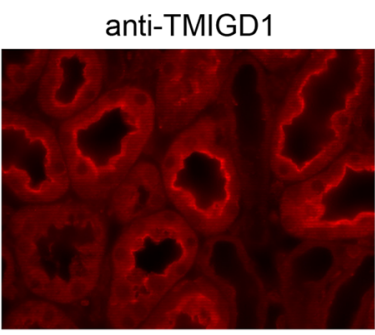

B



Merge/Nuclei
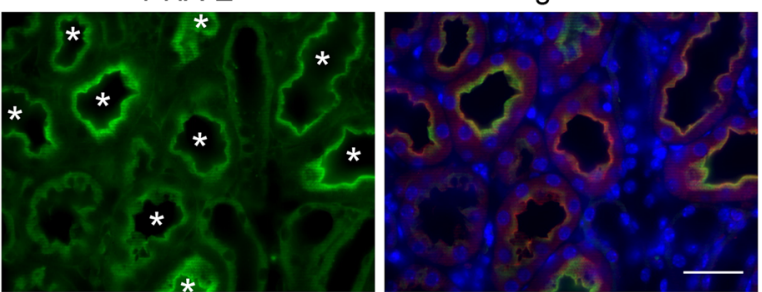

Fig. 2 TMIGD1 is expressed by renal epithelial cells with distinct subcellular locations. a Immunofluorescence analysis of murine kidney sections with TMIGD1 antibodies (\#HPA021946). The insets (Inset 1, Inset 2) show magnifications of the areas demarcated with rectangles (I-1, I-2) in the left panel. Note that TMIGD1 is enriched at cell-cell contacts in some tubular epithelial cells but is localized in the cytoplasm in others. Scale bar: $100 \mu \mathrm{m}$. b Immunohistochemistry on murine kidney sections with antibodies against TMIGD1 (\#HPA021946). Control stainings (bottom panel) were performed in the absence of the primary antibodies. Note that TMIGD1 is expressed by tubular epithelial cells but is absent from glomerular cells. Scale bars: 50 Mm. c Immunofluorescence analysis of murine kidney sections. Kidney sections were stained with FITC-conjugated PHA-E lectin and with anti-TMIGD1 antibodies (\#HPA021946). Note that all TMIGD1-positive structures are positive for PHA-E (marked by asterisks) suggesting preferential expression of TMIGD1 by epithelial cells of proximal tubules. Scale bar: $100 \mu \mathrm{m}$

\section{$\mathrm{N}$-glycosylation of $\triangle \mathrm{D} 1-\mathrm{TMIGD1}$ regulates its cell surface localization}

Cell surface localization of integral membrane proteins is regulated by glycosylation [26]. TMIGD1 contains five potential N-linked glycosylation sites (consensus: $\mathrm{N}-\mathrm{X}$ - S/T/C, X = any AA except P) in the EC domain and has been described to be N-glycosylated [14]. We therefore analyzed the glycosylation of TMIGD1 in HEK293T cells and MDCKII cells. Treatment of cell lysates obtained from TMIGD1-expressing HEK293T cells with PNGaseF, an endoglycosidase that efficiently removes almost all N-linked oligosaccharides from glycoproteins, resulted in a shift of the $\mathrm{M}_{\mathrm{r}}$ of TMIGD1 from approximately $43 \mathrm{kDa}$ to approx. Twenty-seven $\mathrm{kDa}$, which corresponds to the predicted $M_{r}$ of the unglycosylated Flagtagged protein $(27.6 \mathrm{kDa})$ (Fig. 3a). Similarly, PNGaseF treatment of lysates obtained from MDCKII cells expressing the various TMIGD1 constructs depicted in
Fig. 1a resulted in a shift to the $M_{r}$ expected from the unmodified proteins in all constructs (Fig. $3 \mathrm{~b}$ ) indicating that all constructs are $\mathrm{N}$-glycosylated. Of note, the TMIGD1 constructs lacking the D1 Ig-like domain $(\Delta \mathrm{D} 1$-TMIGD1, $\Delta \mathrm{D} 1-\mathrm{TMIGD} 1 / \Delta 5)$ showed an abundant protein species with a $M_{r}$ similar to the constructs containing both Ig-like domains (Fig. 3b). PNGaseF treatment completely abolished this high $\mathrm{M}_{\mathrm{r}}$ species, indicating that this protein species results from hyperglycosylation. The increased glycosylation of TMIGD1 in the absence of the D1 Ig-like domain might result from an unmasking of $\mathrm{N}$-linked glycosylation sites that are not accessible for glycosylation in the full length protein.

To further address the glycosylation of the TMIGD1 constructs in MDCKII cells, cells were treated for $20 \mathrm{~h}$ with tunicamycin, an inhibitor of $\mathrm{N}$-glycosidic linkage formation in glycoprotein synthesis, and analyzed by Western blotting with antibodies against Flag-tagged 
A

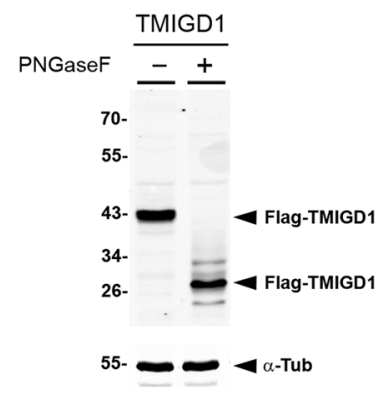

C

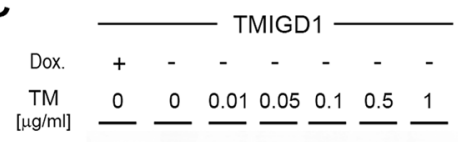

70 -

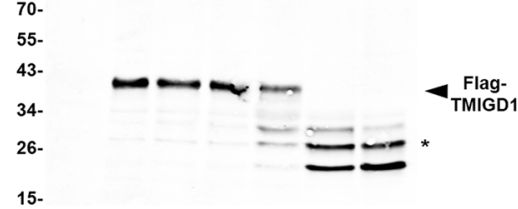

15-
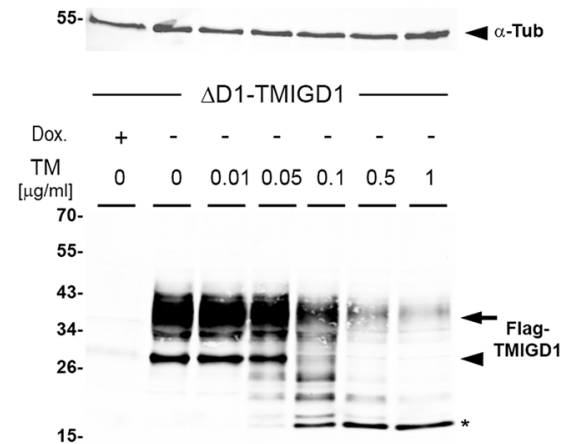

15.



B
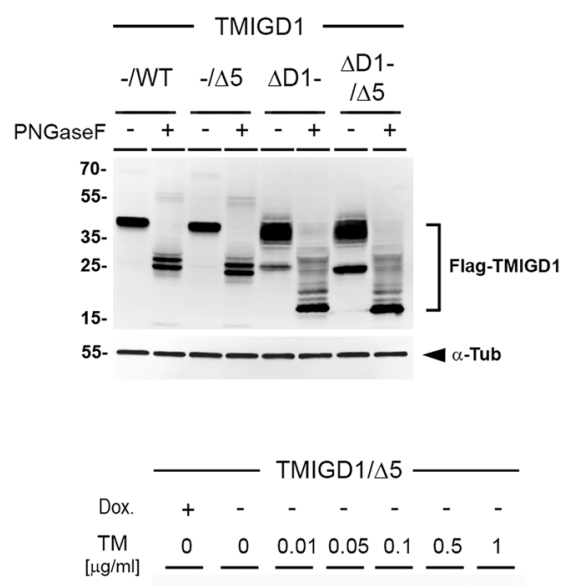

70.

$55-$



15-
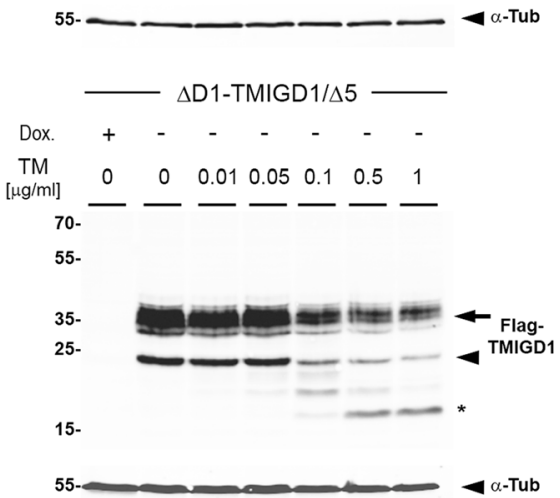

D

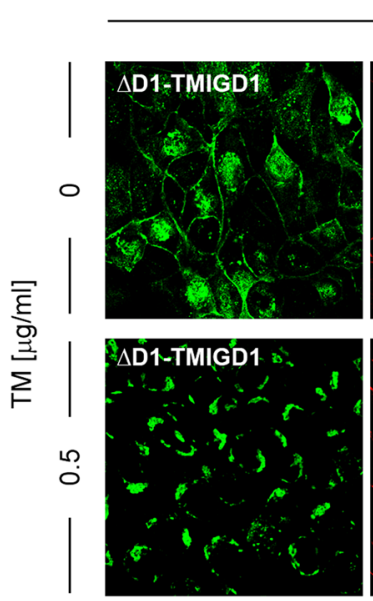

$\Delta \mathrm{D} 1-\mathrm{TMIGD} 1$
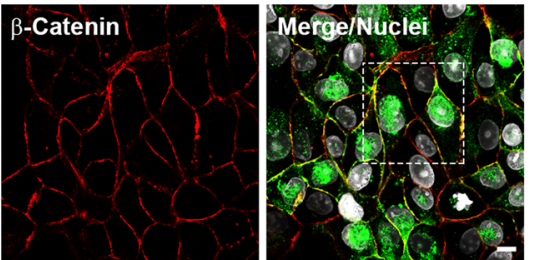

Merge: Zoom


Fig. 3 (See legend on next page.) 


\section{(See figure on previous page.)}

Fig. $3 \mathrm{~N}$-glycosylation regulates TMIGD1 localization at cell-cell contacts. a Lysates obtained from Flag-TMIGD1-expressing HEK293T cells were incubated with PNGaseF, separated by SDS-PAGE and analyzed by Western blotting with antibodies against the Flag tag. Note that the electrophoretic mobility of TMIGD1 shifts to a $M_{r}$ that corresponds to the $M_{r}$ expected for the unglycosylated protein, indicating that TMIGD1 is decorated exclusively with N-linked carbohydrates. $\mathbf{b}$ Lysates obtained from MDCKIl cell lines expressing Flag-tagged TMIGD1 constructs (TMIGD1/WT (-/WT), TMIGD1/ $\Delta 5(-/ \Delta 5), \Delta \mathrm{D} 1-\mathrm{TMIGD1}(\Delta \mathrm{D} 1-), \Delta \mathrm{D} 1-\mathrm{TMIGD} 1 / \Delta 5(\Delta \mathrm{D} 1-/ \Delta 5)$ were incubated with PNGaseF and analyzed by Western blotting with antibodies against the Flag tag. The electrophoretic mobilities of all TMIGD1 constructs shift to $\mathrm{M}_{\mathrm{r}}$ that correspond to the $M_{r}$ expected for the unglycosylated proteins. Note that the absence of the $D 1$ domain $(\Delta D 1, \Delta D 1-/ \Delta 5$ constructs) results in a protein species with a $\mathrm{M}_{\mathrm{r}}$ similar to that of the full length proteins ( $\mathrm{WT}$, $/ \Delta 5$, respectively). These protein species most likely result from hyperglycosylation in the absence of the D1 Ig-like domain. c MDCKII cell lines described in (b) were incubated for $20 \mathrm{~h}$ with various concentrations of tunicamycin. Lysates were analyzed by Western blotting with antibodies against the Flag tag. Arrowheads indicate the TMIGD1 isoforms in the absence of tunicamycin treatment, asterisks indicate the TMIGD1 isoforms expected from the unmodified proteins. Protein bands above and below the protein bands marked by asterisks most likely represent incompletely deglycosylated protein species and degradation products due to the lack of glycosylation, respectively. $\mathbf{d} \triangle D$ D1-TMIGD1-expressing MDCKII cells were fixed with methanol and double-stained with antibodies against the Flag tag and against $\beta$-catenin. Flag- $\triangle \mathrm{D} 1-\mathrm{TMIGD1}$ is completely absent from cell-cell contacts after treatment with $0.5 \mathrm{\mu g} / \mathrm{ml}$ tunicamycin. Abbreviations: Dox., doxycycline, TM, tunicamycin, $a$-tub, a-tubulin. Scale bars: $10 \mu \mathrm{m}$

TMIGD1. Similar to the treatment of lysates with PNGaseF, incubation of cells with tunicamycin resulted in a dose-dependent shift of the $M_{r}$ of all TMIGD1 constructs to lower $M_{r}$ species (Fig. 3c). The high $M_{r}$ species observed for the two $\Delta \mathrm{D} 1$ constructs were strongly reduced in the presence of $1 \mu \mathrm{g} / \mathrm{ml}$ tunicamycin confirming that these species result from $\mathrm{N}$-glycosylation. To test if this hyperglycosylation is involved in the cell surface and cell-cell contact localization of $\Delta \mathrm{D} 1$ TMIGD1, we analyzed its localization by immunocytochemistry. In the presence of tunicamycin, $\Delta \mathrm{D} 1$ TMIGD1 was completely absent from intercellular junctions but was present in the cytoplasm, most likely in the Golgi apparatus (Fig. 3d, Suppl. Fig. 1). Together, these observations suggest that the junctional localization of TMIGD1 is regulated by $\mathrm{N}$-glycosylation and that one (or more) $\mathrm{N}$-glycosylation sites required for junctional localization might be masked in the full length protein.

\section{TMIGD1 is localized in mitochondria in subconfluent cells and is recruited to intercellular junctions during maturation in HK-2 kidney epithelial cells}

Given the preferential cytoplasmic localization of ectopically expressed TMIGD1 in distal tubule-derived kidney MDCKII epithelial cells (Fig. 1) and the different localization and expression of TMIGD1 in proximal vs distal kidney tubules (Fig. 2), we analyzed the localization of endogenous TMIGD1 in HK-2 cells, a human renal epithelial cell line derived from proximal tubules [27]. At low cell density TMIGD1 was localized in a cytoplasmic compartment. Co-stainings with markers specific for mitochondria (MitoTracker), the Golgi apparatus (p230TG), or early endosomes (EEA-1), revealed localization of TMIGD1 in mitochondria but not in the Golgi apparatus or in early endosomes (Fig. 4a). When cells were grown to higher densities, TMIGD1 gradually localized at cell-cell contacts with the highest number of TMIGD1-positive cells and strongest TMIGD1 signal intensity being observed at 12 days of confluency (Fig. 4b). These observations indicated that TMIGD1 can localize to both mitochondria and to intercellular junctions, and that the localization at cell-cell junctions is regulated by cell density.

To confirm the specificity of the antibody-generated signals in mitochondria of sparse cells and at cell-cell junctions of confluent cells, we transfected HK-2 cells with a vector that allows inducible expression of a TMIGD1 shRNA and analyzed the cells under sparse and confluent growth conditions. Both the mitochondrial signal and the cell junction-associated signal were largely abolished after shRNA-mediated knockdown of TMIGD1 (Fig. 4c) confirming TMIGD1 as a duallocation protein.

\section{TMIGD1 interacts with SYNJ2BP}

To identify molecules that interact with TMIGD1 and possibly regulate its localization in mitochondria, we performed a yeast-two hybrid screen using the cytoplasmic tail of TMIGD1 as bait and a murine embryonic cDNA library $[28,29]$. We isolated a cDNA fragment that covered nucleotides 78 to 448 of the murine SYNJ2BP cDNA and that encompassed AA 1-105 of the murine SYNJ2BP isoform 1 [30]. This clone encodes for the entire PDZ domain of SYNJ2BP (AA13-100) with only a few additional AA flanking the PDZ domain at both termini (Fig. 5a), which strongly suggests a PDZ domain-dependent interaction between TMIGD1 and SYNJ2BP. To verify this interaction we performed GSTpulldown experiments. GST-TMIGD1 cytoplasmic domain fusion proteins immobilized on GSH-sepharose were incubated with lysates obtained from SYNJ2BPtransfected HEK293T cells. SYNJ2BP was precipitated with the wildtype cytoplasmic domain of TMIGD1 but not with a deletion mutant lacking the PDZ domainbinding motif (TMIGD1/ $\Delta 5$, Fig. $5 \mathrm{~b}$ ). These findings confirmed that TMIGD1 interacts with SYNJ2BP and indicated that this interaction requires the PDZ domainbinding motif of TMIGD1. To address an interaction 


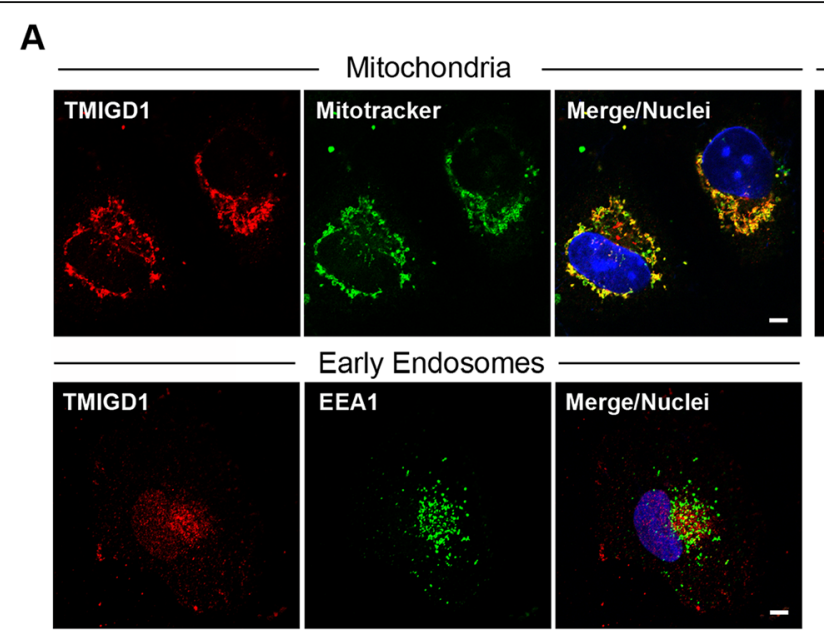

B

sparse

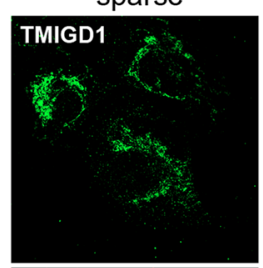

Mitotracker

(1)
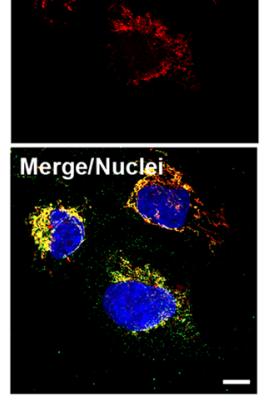

Day 1

Day 4

Day 12
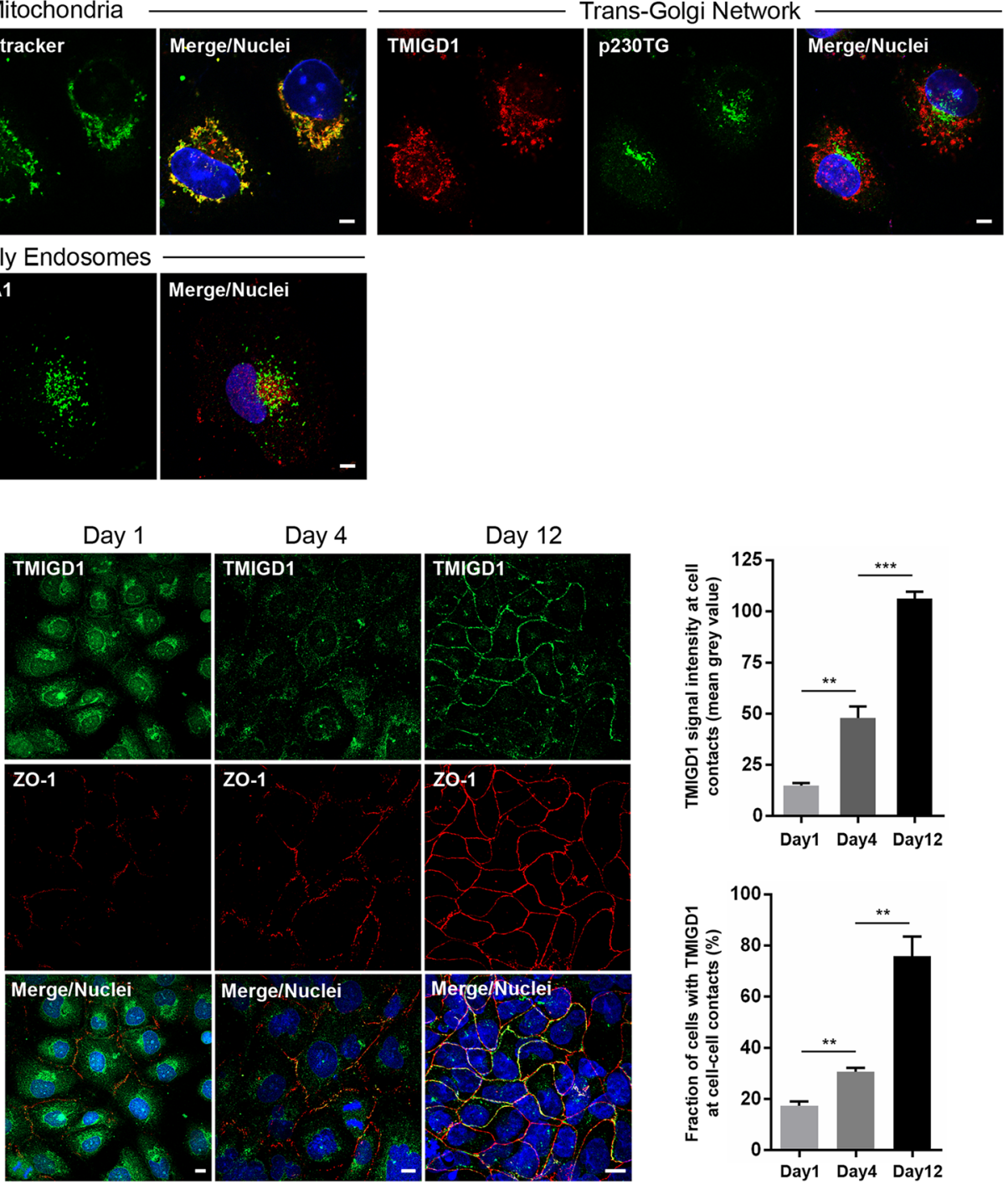

C

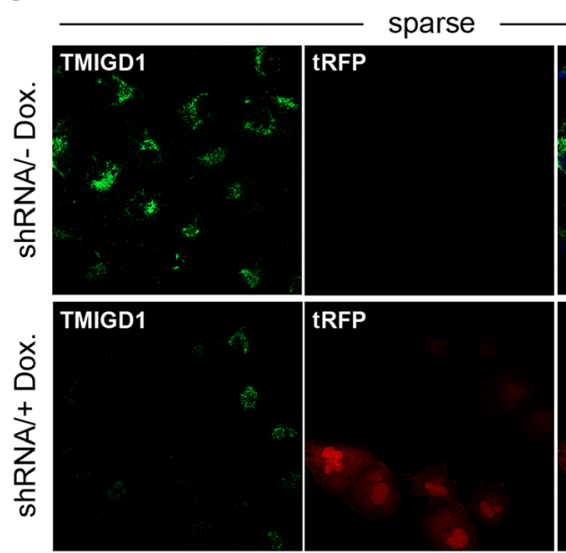

confluent
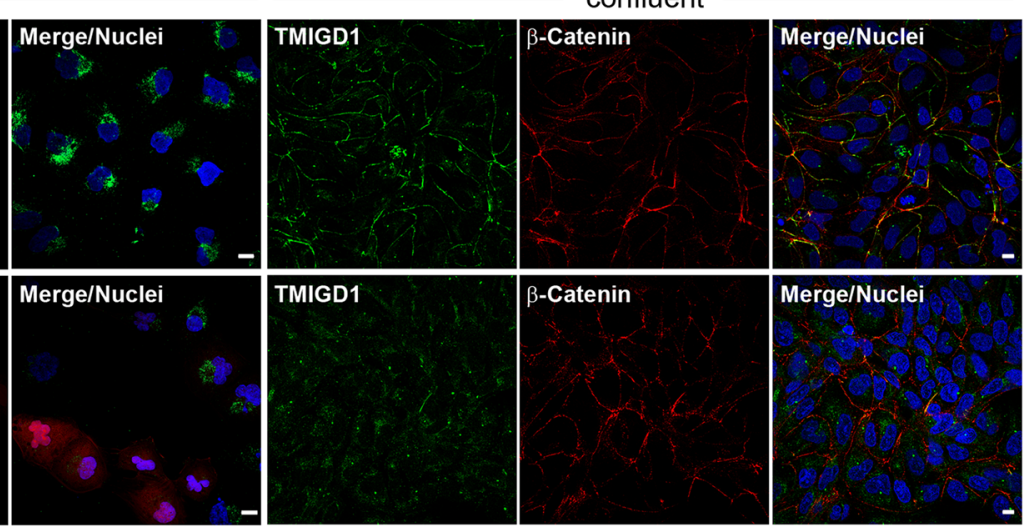

Fig. 4 (See legend on next page.) 
(See figure on previous page.)

Fig. 4 TMIGD1 localizes to mitochondria and cell-cell contacts in HK-2 cells. a Sparsely grown HK-2 cells were fixed and stained with polyclonal antibodies against TMIGD1 (\#HPA021946) and markers for mitochondria (MitoTracker), the trans-Golgi network (p230TG) and early endosomes (EEA1). Note that TMIGD1 localizes specifically to mitochondria. Scale bars: $5 \mu \mathrm{m}$. $\mathbf{b}$ HK-2 cells were grown as single cells or were grown and maintained at confluency for different periods of time, as indicated. Cells were fixed and stained with antibodies against TMIGD1 (\#HPA021946) and MitoTracker (sparsely grown cells), or with antibodies against TMIGD1 (\#HPA021946) and the cell-cell contact marker ZO-1 (cells grown to confluency). Right panels: Quantification of TMIGD1 signal intensities at cell-cell contacts (top bar graph) and of fraction of cells with TMIGD1positive cell-cell contacts at different days of confluency (bottom bar graph). Quantification of TMIGD1 signal intensities at cell-cell contacts (top bar graph) was performed as described in the Methods section. Statistical analysis was performed using unpaired Student's t-test. Data were obtained from three independent experiments and are presented as arithmetic means \pm SEM; ${ }^{* *} P<0.01,{ }^{* * *} P<0.001$. Scale bars: $10 \mu \mathrm{mm}$. c HK-2 cells stably transfected with the plnducer10-mir-RUP-PheS plasmid vector that allows expression of both a TMIGD1-specific shRNA and turboRFP (tRFP) under a doxycycline-regulated promoter were grown to low confluency (sparse) or high confluency (confluent), fixed with PFA and methanol, respectively, and analyzed by fluorescence microscopy with antibodies against TMIGD1 (\#HPA021946) and the cell contact marker $\beta$ catenin, as indicated. In sparsely grown cells, the tRFP signal encoded by the plnducer10 vector was used as marker for shRNA-expressing cells. Note that the plnducer10 vector is based on a TetON system, i.e. shRNA expression is induced by doxycycline. Scale bars: $10 \mu \mathrm{m}$

between TMIGD1 and SYNJ2BP in cells, we performed co-immunoprecipitation (CoIP) experiments. SYNJ2BP co-immunoprecipitated with TMIGD1 from transfected HEK293T cells (Fig. 5c), indicating that TMIGD1 and SYNJ2BP interact in cells. Together, these observations identify SYNJ2BP as binding partner of TMIGD1 that interacts with TMIGD1 through a direct PDZ domaindependent interaction.

Since SYNJ2BP is described as a protein that localizes to mitochondria and to the plasma membrane [16-20], we analyzed its localization in HK-2 cells grown to different densities. Similar to what we observed for TMIGD1, SYNJ2BP localized predominantly to mitochondria in sparse cells but was localized at cell-cell contacts when grown to confluency (Fig. 5d). When cells were grown for 7 or 12 days at confluency, SYNJ2BP was no longer present at cell-cell contacts but localized predominantly in the cytoplasm (Fig. 5d). These observations indicate that similar to TMIGD1, SYNJ2BP shows a dynamic localization at cytoplasmic compartments and at cell-cell junctions in a confluency-dependent manner.

\section{SYNJ2BP can recruit TMIGD1 to mitochondria}

To establish a functional interaction between TMIGD1 and SYNJ2BP, we ectopically expressed Myc-tagged SYNJ2BP in TMIGD1-transfected MDCKII-TetOFF cell lines (depicted in Fig. 1) and analyzed the localization of TMIGD1 by immunofluorescence microscopy. Transfected Myc-SYNJ2BP localized exclusively to mitochondria and was absent from cell-cell contacts in all cell lines tested (Fig. 6). TMIGD1/WT was recruited from cytoplasmic compartments to mitochondria in approximately $75 \%$ of Myc-SYNJ2BP-expressing cells (Fig. 6a), suggesting that SYNJ2BP can recruit TMIGD1 to mitochondria. The $\triangle \mathrm{D} 1-\mathrm{TMIGD1}$ construct, which is localized at cell-cell contacts in the absence of ectopic SYNJ2BP (Fig. 1c, e; Fig. 3d), was recruited to mitochondria in more than $90 \%$ of Myc-SYNJ2BP-expressing cells (Fig. 6b). Deletion of the PDZ domain-binding motif in
$\Delta$ D1-TMIGD1 $(\Delta \mathrm{D} 1-\mathrm{TMIGD} 1 / \Delta 5)$ resulted in a complete retention of this construct at cell-cell junctions (Fig. 6c). These findings indicate that SYNJ2BP can recruit TMIGD1 to mitochondria, and that this recruitment is mediated by the PDZ domain-binding motif of TMIGD1.

\section{Discussion}

In the present study, we characterize the subcellular localization of TMIGD1, a cell adhesion receptor that is expressed in epithelial cells of the intestine and the kidney $[8,9,14]$. In MDCKII cells, a kidney epithelial cell line derived from distal tubules [21], TMIGD1 is localized predominantly in the cytoplasm. Deletion of the membrane-distal Ig-like domain of TMIGD1 results in transport to the cell surface and cell-cell contact localization. The localization of this construct at cell-cell contacts correlates with increased N-linked glycosylation, suggesting that this localization can be regulated by $\mathrm{N}$-glycosylation. Experiments with domain swapping mutants indicate that both the extracellular domain and the cytoplasmic domain of TMIGD1 contribute to its localization at cell-cell contacts. Surprisingly, in HK-2 cells, a kidney epithelial cell line derived from proximal tubules [27], TMIGD1 localizes to mitochondria when cells are grown at low confluency but is recruited to cell-cell contacts with increasing cell density. Our findings thus identify TMIGD1 as an adhesion receptor with different subcellular localization and indicate that its subcellular localization can be regulated by cell density.

We identified SYNJ2BP as an interaction partner of TMIGD1, providing a possible explanation for the localization of TMIGD1 in mitochondria in HK-2 cells. The SYNJ2BP cDNA clone isolated from the murine Y2H library comprised AA 1-105 of SYNJ2BP, which represents almost exclusively the $\mathrm{PDZ}$ domain of SYNJ2BP (AA 13-100). GST-pulldown experiments indicated that the PDZ domain-binding motif of TMIGD1 (-SETAL) is required for the interaction with SYNJ2BP. 


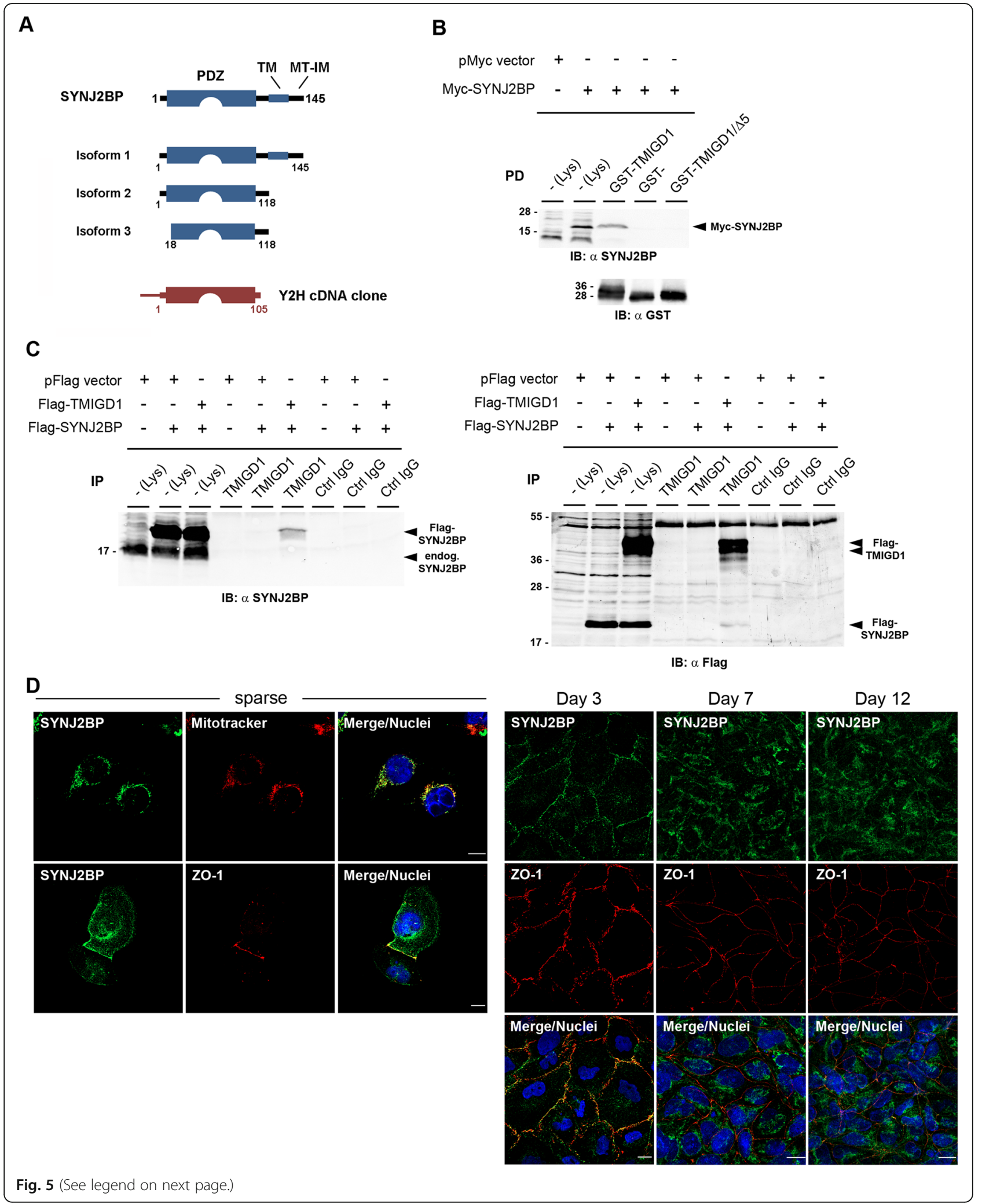


(See figure on previous page.)

Fig. 5 TMIGD1 interacts with SYNJ2BP. a Schematic presentation of murine Synj2bp isoforms. The TMIGD1-interacting fragment isolated from the yeast-two hybrid library (indicated in red) encodes AA 1-105 of Synj2bp and encompasses the entire PDZ domain (AA 13-100). Abbreviations: TM, transmembrane, MT-IM, mitochondrial intermembrane (b) TMIGD1 interacts with SYNJ2BP through its PDZ domain-binding motif. Lysates of SYNJ2BP-transfected HEK293T cells were incubated with GST-fusion proteins containing the entire cytoplasmic domain of TMIGD1 (GST-TMIGD1) or the cytoplasmic domain lacking the PDZ domain-binding motif (GST-TMIGD1/D5) or with GST alone (GST-). Precipitates obtained with GST fusion proteins were immunoblotted with anti-SYNJ2BP antibodies (Sigma \#HPA000866, top panel, 90\% of precipitates) or with anti-GST antibodies (bottom panel, 10\% of precipitates). SYNJ2BP precipitated with GST-TMIGD1 but not with GST-TMIGD1/A5. Abbreviations: IB, immunoblotting; Lys, Iysate. c SYNJ2BP co-immunoprecipitates with TMIGD1. Immunoprecipitates obtained with anti-TMIGD1 polyclonal antibodies (Affi1611) from HEK293T cells transfected with empty vector (pFlag vector), Flag-TMIGD1 and/or Flag-SYNJ2BP as indicated were immunoblotted with anti-SYNJ2BP antibodies (Sigma \#HPA000866, left panel, 90\% of precipitates) or with anti-Flag antibodies (right panel, 10\% of precipitates). Note that SYNJ2BP is present in TMIGD1 immunoprecipitates. Abbreviations: endog., endogenous; IB, immunoblotting; IP, immunoprecipitation; Lys, lysate. d SYNJ2BP localizes at mitochondria in sparsely seeded cells but to cell-cell contacts in confluent cells. HK-2 cells were either sparsely seeded or grown to confluency for $3 \mathrm{~d}$, 7d, or $12 \mathrm{~d}$ as indicated, then fixed and stained for SYNJ2BP and either Mitotracker or ZO-1 as indicated. Scale bars: $10 \mu \mathrm{m}$

In addition, ectopically expressed SYNJ2BP recruited $\triangle D 1-T M I G D 1$ efficiently to mitochondria whereas the same construct lacking the PDZ binding motif $(\triangle \mathrm{D} 1$ TMIGD1/ $\Delta 5$ ) was retained at cell-cell contacts (Fig. 6). Our observations therefore strongly suggest a direct and PDZ domain-dependent interaction between TMIGD1 and SYNJ2BP.

SYNJ2BP, a.k.a. as mitochondrial outer membrane protein 25 (OMP25) or activin receptor-interacting protein 2 (Arip2), has originally been described as a mitochondria-associated protein of 145 AA [16]. SYNJ2BP consists of a PDZ domain (AA 13-100) that localizes in the cytoplasm, a transmembrane domain (TMD, AA 118-138) through which the protein is inserted in the outer mitochondrial membrane, and a short C-terminus (AA 139-145) that extends into the mitochondrial intermembrane region [16, 17] (Fig. 5a). Two out of three identified splice variants lack the TMD and thus are expected to localize exclusively in the cytoplasm [30]. Interestingly, SYNJ2BP has been found to interact with the cytoplasmic domain of activin type II receptors (ActRII) to regulate their endocytosis [18], as well as with the cytoplasmic domains of the Notch ligands Delta like protein (DLL) 1 and DLL4 to increase protein stability and Notch signalling [19]. Together, these observations demonstrate that SYNJ2BP is a dual location protein which can be targeted to mitochondria as well as to the plasma membrane, a property that is shared with TMIGD1.

The biological function of TMIGD1 localized at mitochondria of kidney-derived HK-2 cells is unclear. Mitochondria are the major site of ATP production in cells and also a major source of reactive oxygen species (ROS), such as superoxide and hydrogen peroxide [31]. An imbalance between ROS generation and ROS removal by antioxidant defense mechanisms results in oxidative stress. Importantly, mitochondrial dysfunction is a contributing factor in many diseases, and oxidative stress as a result of mitochondrial dysfunction has been described to contribute to the pathogenesis of kidney disease [32, 33]. Intriguingly, TMIGD1 has been shown to play a protective role during $\mathrm{H}_{2} \mathrm{O}_{2}$-induced oxidative stress in cultured HK-2 cells [14]. In vivo, TMIGD1 expression undergoes a biphasic up- and downregulation in two kidney disease models characterized or favoured by excessive ROS generation, i.e. ischemia/reperfusioninduced oxidative stress and experimentally induced hypertension [14]. Our findings of an interaction between TMIGD1 and SYNJ2BP provide a first insight into a possible mechanism through which TMIGD1 could be targeted to mitochondria where it could possibly exert its function in protecting against oxidative stress.

Mitochondria are also involved in cell metabolism and signalling processes [34]. In recent years, accumulating evidence indicates that extracellular proteins as well as plasma membrane-resident proteins are translocated to mitochondria to regulate cellular functions. For example, the epidermal growth factor receptor (EGFR) is translocated to mitochondria where it phosphorylates the cytochrome c oxidase subunit II (CoxII) to reduce CoxII activity and cellular ATP [35]. EGFR translocation to mitochondria can also be triggered by apoptosis inducers and by EGFR kinase inhibitors, which renders cells more resistant to pharmacologically induced apoptosis [36]. In endothelial cells, soluble antiangiogenic proteins like angiostatin or isthmin are internalised through the endocytic pathway and trafficked to mitochondria through the direct fusion of late endosome (LE) with mitochondria, where they execute apoptosis $[37,38]$. Interestingly, SYNJ2BP has been found to mediate the tethering of mitochondria to the rough ER through an interaction that involves its cytosol-exposed PDZ domain and the C-terminal PDZ domain-binding motif of the ER membraneinserted ribosome-binding protein 1 (RRBP1) [39]. It is therefore possible that increased endocytosis of TMIGD1 in subconfluent cells regulates the trafficking and/or targeting of LE to mitochondria via a TMIGD1 - SYNJ2BP interaction, where it could play a protective role during oxidative stress [14]. 


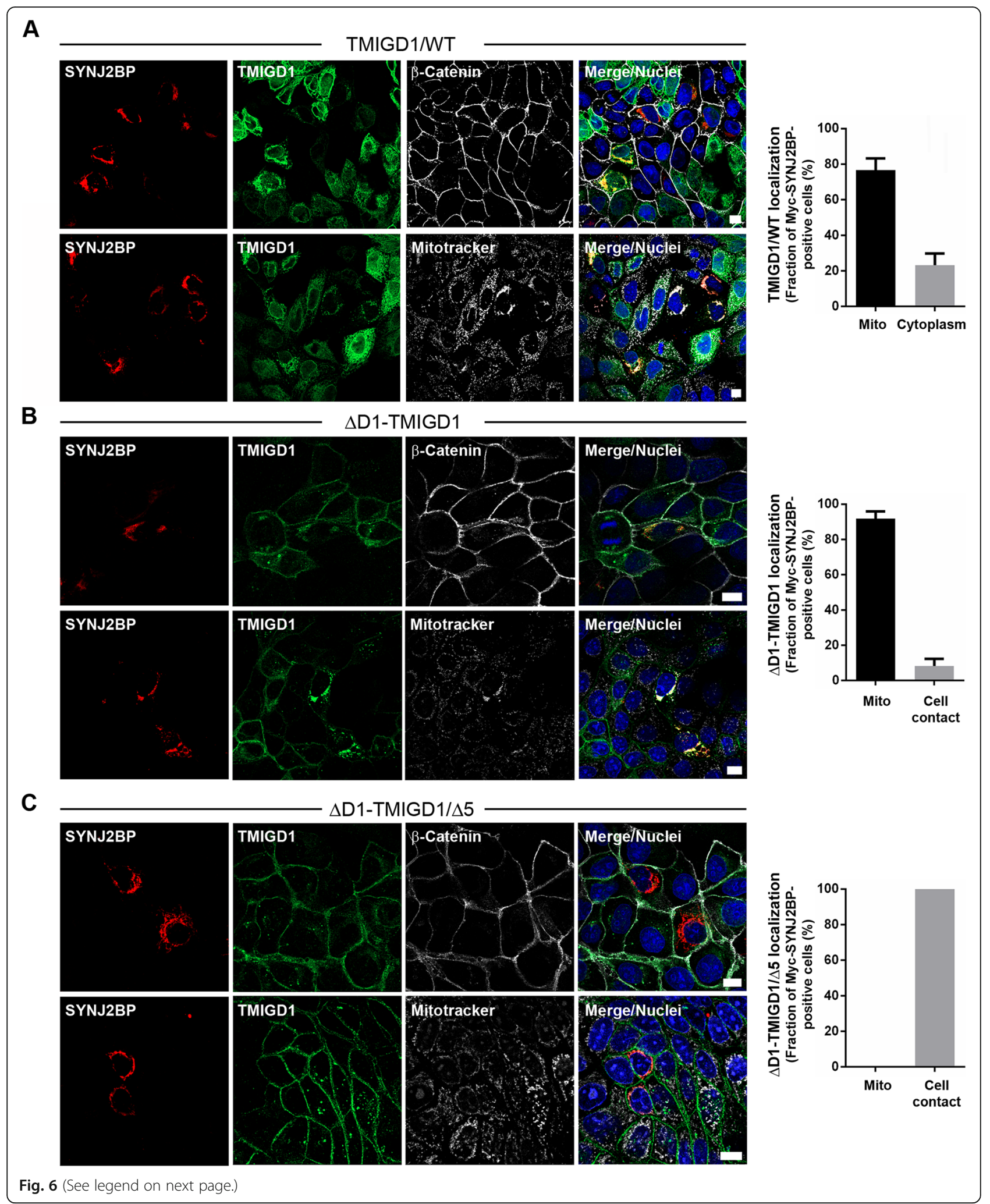




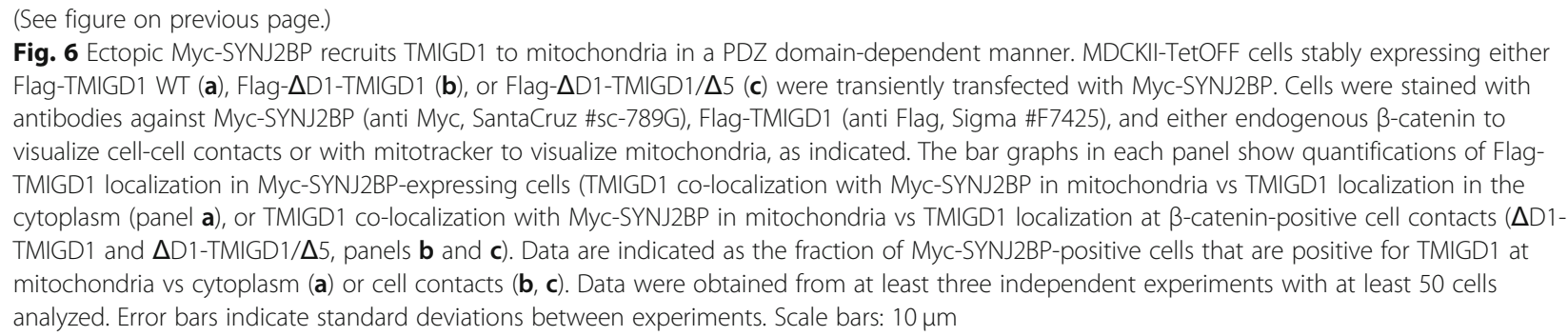

The biological function of TMIGD1 at cell-cell contacts is also unknown. TMIGD1 undergoes homophilic interactions and promotes cell aggregation when ectopically expressed in HEK293 cells [14]. These observations support an adhesive function of TMIGD1. Consistent with this, TMIGD1 expression reduces proliferation and cell migration, and increases the barrier properties of HEK293 cells [14]. These findings, together with our observation of a gradual increase in cell-cell contact localization of TMIGD1 with increasing cell density (Fig. 4) suggest that TMIGD1 plays a signalling role that is triggered by trans-homophilic interactions between TMIGD1 molecules on opposing cells, which would be similar to what has been described for members of the JAM family [23]. More work has to be invested to understand the biological role of TMIGD1 in more detail.

\section{Conclusions}

In conclusion, we find that the cell adhesion receptor TMIGD1 can localize to both mitochondria and cell-cell contact sites in renal epithelial cells, and that its localization is regulated by cell confluency. We identify the mitochondrial outer membrane protein SYNJ2BP as interaction partner of TMIGD1, and we find that SYNJ2BP can recruit TMIGD1 to mitochondria. Our findings provide a first insight into a potential molecular basis for the role of TMIGD1 as protector against oxidative stress.

\section{Methods}

\section{Cell culture and transfections}

HK-2 cells (ATCC CRL-2190) were grown in DMEM/F12 (3:1) (Sigma-Aldrich \#D5671/ Sigma-Aldrich \#51651C) containing $10 \%$ FCS, $2 \mathrm{mM}$ glutamine, $100 \mathrm{U} / \mathrm{ml}$ penicillin and $100 \mathrm{U} / \mathrm{ml}$ streptomycin. HEK293T cells (ATCC CRL3216) and MDCK II Tet-Off cells (TakaraBio-Clontech, St-Germain-en-Laye, \# 630913/631138) were grown in DMEM containing $10 \%$ FCS, $2 \mathrm{mM}$ glutamine, $100 \mathrm{U} / \mathrm{ml}$ penicillin and $100 \mathrm{U} / \mathrm{ml}$ streptomycin. MDCK II Tet-Off cell lines stably expressing human wildtype TMIGD1 (TMIGD1), TMIGD1 lacking the C-terminal PDZ domain-binding motif (TMIGD1/A5), a TMIGD1 mutant lacking the membrane-distal Ig-domain ( $\triangle D 1$-TMIGD1), or a TMIGD1 mutant lacking both the membrane-distal Ig-domain and the PDZ domain-binding motif $(\triangle D 1$ TMIGD1/ $\Delta 5$ ) were generated by electroporation and subsequent selection by growth in DMEM medium supplemented with $100 \mu \mathrm{g} / \mathrm{ml} \mathrm{G418}, 1 \mu \mathrm{g} / \mathrm{ml}$ puromycin, $150 \mu \mathrm{g} / \mathrm{ml}$ hygromycin and $50 \mathrm{ng} / \mathrm{ml}$ doxycycline. Expression of transgenes was induced by transferring cells into medium lacking doxycycline using tetracycline-free FCS (BD Biosciences) as described [22]. HK-2 cells stably expressing a TMIGD1-specific shRNA (5'-CCAGGCTCAA ATGATGTGGTA-3') under a doxycycline-regulated promoter (TetON) were generated by lentiviral transduction with pInducer10-mir-RUP-PheS (Addgene plasmid \#44011 [40];). Expression of shRNAs was induced with $1 \mu \mathrm{g} / \mathrm{ml}$ doxycycline. Transient transfections of HEK293T cells and MDCK cells were performed with Xfect reagent (TakaRaBio-Clontech \#631318) and Lipofectamine 2000 reagent (Thermo Fisher Scientific \#11668027), respectively, acc. to the manufacturers instructions.

The following plasmid vectors were newly generated: pKE576hyg is a pTRE2hyg (TakaraBio-Clontech)-based plasmid vector that contains the preprotrypsin signal sequence followed by a Flag tag to allow doxycyclineregulated (TetOFF) expression of Flag-tagged constructs. pKE1079 is a pFlag-CMV-1 (Sigma-Aldrich, Munich, Germany)-based plasmid vector that contains EGFP in the multiple cloning site to allow for the expression of Flag-tagged EGFP-constructs.

The following constructs were used. Flag-TMIGD1 constructs in pFlag-CMV-1 (Sigma-Aldrich, Munich, Germany): human full length TMIGD1 without signal peptide (AA 30-262) and human full length TMIGD1 without signal peptide lacking the PDZ domain binding motif (hTMIGD1/A5, AA 30-258). Flag-TMIGD1 constructs in pKE576hyg: hTMIGD1 (AA 30-262), hTMIGD1/A5 (AA 30-257), h $\Delta$ D1-TMIGD1 (lacks membrane-distal Ig-like domain, AA 115-262), h $\Delta \mathrm{D} 1$ TMIGD1/A5 (AA 115-257). EGFP-TMIGD1 constructs in pKE1079 (EGFP inserted between AA211 and AA212 of TMIGD1): EGFP-hTMIGD1 (AA 30-262). TMIGD1/ JAM-A domain swapping constructs in pKE1079: EGFPTMIGD1-JAM-A ( $\mathrm{NH}_{2}$-TMIGD1 ${ }_{30-211}$-EGFP-JAM-A ${ }_{231-}$ 
299-COOH); EGFP-JAM-A-TMIGD1 ( $\mathrm{NH}_{2}-\mathrm{JAM}-\mathrm{A}_{28-230^{-}}$ EGFP-TMIGD1 $1_{211-262}$-COOH). EGFP-JAM-A constructs in pKE1079: EGFP-hJAM-A (AA 28-299; EGFP inserted between AA230 and AA231 of JAM-A). GST-TMIGD1 and GST-TMIGD1/A5: hTMIGD1 cytoplasmic tail (AA 242-262) and hTMIGD1 cytoplasmic tail lacking the PDZ domain binding motif (AA 242-257), respectively, in pGEX-4 T-1 (GE Healthcare, Solingen, Germany). pBTM116-TMIGD1: cytoplasmic tail of hTMIGD1 (AA 241-262) in yeast-two hybrid vector PBTM116 [41]. FlagmSynj2bp: murine Synj2bp/Arip2 full length (AA 1-145) in pCS2-pFlag (kindly provided by Dr. Andreas Fischer, DKFZ Heidelberg). Myc-hSYNJ2BP: human SYNJ2BP full length (AA 2-145) in pKE081myc [42].

\section{Antibodies and reagents}

The following antibodies were used in this study: rabbit pAb anti-hSYNJ2BP (Sigma-Aldrich \#HPA000866); rabbit pAb anti-TMIGD1 (Sigma-Aldrich \#HPA021946); rabbit pAb anti-TMIGD1 (Novus \#NBP1-80672); mouse anti-EEA1 (Beckton-Dickinson (BD)-TL \#610154); mouse anti-P230 transGolgi (BD-TL \#611280); mouse anti-GM130 (BD-TL \#610822), mouse mAb anti $\beta$ catenin (BD-TL \#610456); mouse mAb anti-ZO-1 (BDTL \#610966); mouse mAb anti- $\alpha$-Tubulin (Sigma-Aldrich, clone B-5-1-2, \#T5168); mouse mAb anti-Flag M2 (Sigma-Aldrich \#F1804); rabbit pAb anti-Flag (Sigma-Aldrich \#F7425); goat pAb anti-Myc (SantaCruz \#sc789G); mouse mAb anti-Myc 9E10 [43]; goat pAb anti GST (GE Healthcare \#27-4577-01). Rabbit antiTMIGD1 pAb Affi1611 was generated by immunizing rabbits with a synthetic peptide (NGKTENYILDTTPGS) coupled via a C-terminal Cys residue to KLH. The serum obtained from immunized rabbits was purified by affinity chromatography using the immobilized peptide as affinity ligand (Biomatik, Wilmington DE, USA). Secondary antibodies and fluorophore-conjugated antibodies: IRDye $800 \mathrm{CW}$ Donkey anti-Rabbit IgG (LI-COR Biosciences \#926-32,213), IRDye 680CW Donkey antimouse IgG (LI-COR Biosciences \#926-68,072), Alexa Fluor488 Goat anti-rabbit IgG (Thermo-Fisher \#A11034), Alexa Fluor568 Donkey anti-mouse IgG (Thermo-Fisher \# A10037). The following reagents were used: FITC-conjugated phytohemagglutinin (PHA)-E (VectorLabs \#1111, Biozol, Eching, Germany); PNGase F (Sigma \#7367), tunicamycin (Applichem \#A2242,0005), doxycycline (Sigma \#D9891), collagen type I (rat tail type 1 collagen, Advanced BioMatrix \#5163), MitoTracker (MitoTracker Green FM \#M-7514, Mitotracker Red $\mathrm{CM}$-H2-XROS, Invitrogen).

\section{Flow cytometry}

MDCK II Tet-Off cell lines stably expressing FlagTMIGD1 constructs were washed in PBS, incubated for
$10 \mathrm{~min}$ at $37^{\circ} \mathrm{C}$ in PBS / $5 \mathrm{mM}$ EDTA followed by incubation with Accutase ${ }^{\circ}$ (Sigma Aldrich \#A6964) for 10 $\min$ at $37^{\circ} \mathrm{C}$. For the analysis of cell surface-localized proteins, cells were incubated with rabbit pAb anti-Flag in CellWASH (BD \#349524) containing 5\% BSA (1 h, $4{ }^{\circ} \mathrm{C}$ ), followed by incubation with AlexaF488-conjugated anti-rabbit pAb $\left(45 \mathrm{~min}, 4^{\circ} \mathrm{C}\right)$. For intracellular stainings, cells were washed, fixed in PBS / 2\% PFA, and incubated with primary and secondary antibodies in the presence of $0.5 \%$ saponin (Sigma Aldrich \#A47036). After washing, cells were resuspended in CellWASH containing 5\% BSA at $10^{6}$ cells per $\mathrm{ml}$ and analyzed by flow cytometry using a Guava ${ }^{\circ}$ easyCyte ${ }^{\mathrm{Tw}}$ flow cytometer (MerckMillipore). For each sample, 10.000 cells were measured. Results were analysed using the Guava ${ }^{\circ}$ InCyte $^{\mathrm{Tm}}$ software (MerckMillipore) and are plotted as histograms.

\section{Mitochondria labelling with MitoTracker dyes}

Labelling of mitochondria was performed using MitoTracker Red CM-H2XRos or MitoTracker Green FM (Invitrogen) acc. to the manufacturer instructions. Exposure to MitoTracker probes $(150 \mu \mathrm{M})$ was limited to 45 min until cells were washed with PBS and fixed with $4 \%$ PFA.

\section{Yeast two-hybrid screen}

Yeast two-hybrid screening experiments were performed essentially as described [42]. Briefly, the Saccharomyces cerevisiae reporter strain L40 expressing a fusion protein between LexA and the cytoplasmic tail of TMIGD1 (AA 241-262) was transformed with $250 \mu \mathrm{g}$ of DNA derived from a day 9.5/10.5 mouse embryo cDNA library [29] according to the method of Schiestl and Gietz [44]. The transformants were grown for $16 \mathrm{~h}$ in liquid selective medium lacking tryptophan, leucine (SD-TL) to maintain selection for the bait and the library plasmid, then plated onto synthetic medium lacking tryptophan, histidine, uracil, leucine, and lysine (SD-THULL) in the presence of $1 \mathrm{mM} \mathrm{3-aminotriazole.} \mathrm{After} 3$ days at $30^{\circ} \mathrm{C}$, large colonies were picked and grown for additional 3 days on the same selective medium. Plasmid DNA was isolated from growing colonies using a commercial yeast plasmid isolation kit (DualsystemsBiotech, Schlieren, Switzerland). To segregate the bait plasmid from the library plasmid, yeast DNA was transformed into E. coli HB101, and the transformants were grown on M9 minimal medium lacking leucine. Plasmid DNA was then isolated from E. coli HB101 followed by sequencing to determine the nucleotide sequence of the inserts.

\section{Immunoprecipitation and Western blot analysis}

For immunoprecipitations, cells were lysed in lysis buffer (50 mM TrisHCl, pH 7.4, 1\% (v/v) Nonidet P-40 (NP-40, AppliChem, Darmstadt, Germany), $150 \mathrm{mM} \mathrm{NaCl}$, 
protease inhibitors (Complete Protease Inhibitor Cocktail; Roche, Indianapolis, IN) and phosphatase inhibitors (PhosSTOP ${ }^{\mathrm{m}}$, Roche, Indianapolis, IN), $2 \mathrm{mM}$ sodium orthovanadate) for $30 \mathrm{~min}$ on ice. Postnuclear supernatants were incubated with $3 \mu \mathrm{g}$ of antibodies coupled to protein A- or protein G-Sepharose beads (GE Healthcare, Solingen, Germany) overnight at $4{ }^{\circ} \mathrm{C}$. Beads were washed five times with lysis buffer, bound proteins were eluted by boiling in SDS-sample buffer/1 mM DTT. Eluted proteins were separated by SDS-PAGE and analyzed by Western blotting with near-infrared fluorescence detection (Odyssey Infrared Imaging System Application Software Version 3.0 and IRDye $800 \mathrm{CW}$ conjugated antibodies; LI-COR Biosciences, Bad Homburg, Germany).

\section{GST pulldown experiments}

In vitro binding experiments were performed with recombinant GST-fusion proteins purified from E.coli and immobilized on glutathione-Sepharose 4B beads (Life Technologies). Purification of GST fusion proteins was performed as described [42]. For protein interaction experiments the putative partner protein (prey) was expressed in HEK293T cells by transient transfection. Cells were lysed as described for immunoprecipitations. Lysates were incubated with $3 \mu \mathrm{g}$ of immobilized GST fusion protein for $2 \mathrm{~h}$ at $4{ }^{\circ} \mathrm{C}$ under constant agitation. After 5 washing steps in lysis buffer, bound proteins were eluted by boiling for $5 \mathrm{~min}$ in SDS sample buffer, subjected to SDS-PAGE and analyzed by Western blotting using prey-specific antibodies.

\section{Immunocytochemistry and immunohistochemistry}

For immunocytochemistry, cells were grown on collagencoated glass slides. Cells were washed with PBS and fixed with 4\% paraformaldehyde (PFA, Sigma Aldrich) for 7 min. To detect intracellular proteins, PFA-fixed cells were incubated with PBS containing 0.2\% Triton X-100 for 15 min. Alternatively, cells were fixed with methanol by incubation in icecold methanol for $5 \mathrm{~min}$. Cells were washed with $100 \mathrm{mM}$ glycine in PBS, blocked for $1 \mathrm{~h}$ in blocking buffer (PBS, 10\% FCS, 0.2\% Triton X-100, 0.05\% Tween$20,0.02 \%$ BSA) and then incubated with primary antibodies in blocking buffer for $1 \mathrm{~h}$ at room temperature (RT) or overnight at $4{ }^{\circ} \mathrm{C}$. After incubation, cells were washed three times with PBS and incubated with fluorochrome (AlexaFluor488, AlexaFluor594 and AlexaFluor647)-conjugated, highly cross-adsorbed secondary antibodies (Invitrogen) for $2 \mathrm{~h}$ at RT protected from light. F-Actin was stained using phalloidin-conjugates (FITC, TRITC and AlexaFluor647), DNA was stained with 2,4, diamidino-2-phenylindole (DAPI, Sigma-Aldrich). Samples were washed three times with PBS and mounted in fluorescence mounting medium (Mowiol 4-88, Sigma Aldrich).

For immunohistochemistry, kidney tissue of C57BL/6 J male mice, 12 weeks old, was used. All animals were killed by bleeding (thoracotomy and puncture of the left heart ventricle with subsequent opening of the vena cava) under deep isoflurane anesthesia $\left(1 \mathrm{~L} \mathrm{O}_{2} / \mathrm{min} ; 5 \%\right.$ isoflurane). Tissues were fixed in 4\% PFA in PBS for 12 $\mathrm{h}$ and embedded in paraffin. Paraffin-embedded sections were deparaffinized with xylene and rehydrated through graded alcohols to water. Antigen retrieval was performed by boiling the sections in a pressure cooker for 5 min in TE buffer. A standard Dako EnVison $+{ }^{\mathrm{Tm}}$ detection kit (Dako, Glostrup, Denmark) was used according to the manufacturers instructions. For immunfluorescence analyses in the kidney, sections were incubated with anti-TMIGD1 antibodies, followed by incubation with fluorochrome-conjugated secondary antibodies and FITC-conjugated PHA-E (dil 1:200), a marker for proximal kidney tubules [25]. The slides were mounted with aquamount after counterstaining with DAPI for $2 \mathrm{~min}$. Images were acquired using an Axio Zeiss microscope (Axiovert 100; Carl Zeiss, Oberkochen, Germany), equipped with a digital camera (AxiocamMRc; Carl Zeiss) with the AxionVisonLE Release 4.7.1 software (Carl Zeiss). Immunofluorescence microscopy of cultured cells was performed using the confocal microscopes LSM 780 and LSM 800 Airyscan (both from Carl Zeiss, Jena, Germany) equipped with the objectives PlanApochromat $\times 40 / 1.3$ oil differential interference contrast and Plan-Apochromat $\times 63 / 1.4$ oil differential interference contrast (Carl Zeiss). Image processing and quantification was performed using ImageJ, Zen 2 (Blue Edition, Carl Zeiss) and Imaris (Bitplane, Version 9.1.2) software.

\section{Statistics}

For the quantitative analysis of TMIGD1 localization at cell-cell junctions, cells were visually inspected for TMIGD1 immunofluorescence signals. TMIGD1 signals were rated as cell-cell contact-localized when a clear overlap with immunofluorescence signal of cell-cell contact-localized proteins ( $\beta$-catenin in Figs. 1d, f; ZO-1 in Fig. 4b) at linear cell-cell contact sites was observed. For the quantitative analysis of TMIGD1 signal intensities at cell-cell contacts (Fig. 4b) the ImageJ software was used. Cell-cell contacts were identified as ZO-1positive regions. Using a mask covering a defined area of $6.75 \mu \mathrm{m} \times 6.75 \mu \mathrm{m}$ the absolute pixel values at $\mathrm{ZO}-1$ positive cell-cell contacts were measured, and the mean values were calculated. For the quantitative analysis of TMIGD1 recruitment to mitochondria by Myc-tagged SYNJ2BP (Fig. 6), cells were visually inspected for the localization of Myc-SYNJ2BP at mitochondria. TMIGD1 
signals were rated as mitochondria-localized when a clear overlap with the Myc-SYNJ2BP signal at mitotracker-positive mitochondria was observed. Results are expressed either as arithmetic means \pm SEM or \pm SD as indicated. To test the normality of data sample distributions, the D'Agostino-Pearson normality test was used. Data were statistically compared using unpaired, two-tailed Student's $t$-test (cell contacts of stably transfected MDCKII cells), or probed for being statistically different from a fixed value using One sample $t$-test. Statistical analyses were performed using GraphPad Prism version 6 (GraphPad Software, San Diego, CA). Pvalues are indicated as follows: ${ }^{*} P<0.05$, ${ }^{* *} P<0.01$, *** $P<0.001$ and $* * * P<0.0001$.

\section{Supplementary information}

Supplementary information accompanies this paper at https://doi.org/10. 1186/s12860-020-00274-1.

Additional file 1: Suppl. Fig. 1. $\triangle \mathrm{D} 1-\mathrm{TMIGD} 1$ is retained in the cisGolgi compartment in the presence of tunicamycin. $\triangle \mathrm{D} 1-\mathrm{TMIGD1-}$ expressing MDCKII-TetOFF cells were incubated with tunicamycin as indicated. Cells were fixed with methanol and double-stained with antibodies against the Flag tag to detect $\triangle \mathrm{D} 1-\mathrm{TMIGD1}$ and with either Mitotracker Red to visualize mitochondria (top panels), or with antibodies against GM130 (a cis-Golgi matrix protein) (middle panels) or against p230TG (a peripheral membrane protein associated with the cytosolic face of the trans Golgi network) (bottom panels) to visualize Golgi compartments. In tunicamycin-treated cells, $\triangle \mathrm{D} 1$-TMIGD1 shows a partial co-localization with Golgi markers but not with Mitotracker Red. Abbreviations: TM, tunicamycin. Scale bars: $10 \mu \mathrm{m}$.

\section{Abbreviations}

TMIGD1: Transmembrane and immunoglobulin domain-containing protein 1; JAM-A: Junctional Adhesion Molecule-A; SYNJ2BP: Synaptojanin-2-binding protein

\section{Acknowledgements}

We gratefully acknowledge the help of Dr. Andreas Fischer, DKFZ Heidelberg, Germany, for providing us with plasmids encoding SYNJ2BP. We also thank Rita Schröter for excellent technical assistance.

\section{Authors' contributions}

$\mathrm{CH}, \mathrm{YAS}, \mathrm{DK}$ and $\mathrm{KE}$ designed and conceived the study. $\mathrm{CH}, \mathrm{YAS}, \mathrm{NK}, \mathrm{EH}, \mathrm{E}-$ MT, MG-E, FB and SR performed experiments. $\mathrm{CH}, \mathrm{YAS}, \mathrm{DK}, \mathrm{NK}, \mathrm{EH}, \mathrm{SR}, \mathrm{MN}$, $V G$, and $K E$ analyzed the data. $\mathrm{CH}, \mathrm{YAS}$ and KE wrote the manuscript. All authors have read and approved the manuscript.

\section{Funding}

This work was supported by grants from the Deutsche Forschungsgemeinschaft (EB 160/5-1, EB 160/6-1) and from the Medical Faculty of the University of Münster (IZKF Eb2/020/14). We hereby declare that the funding body has no role in the design of the study and collection, analysis, and interpretation of data or in writing the manuscript.

\section{Availability of data and materials}

All data generated or analyzed during this study are included in this published article.

\section{Ethics approval and consent to participate}

Experiments with mice were approved by a governmental committee on animal welfare (Landesamt für Natur, Umwelt und Verbraucherschutz Nordrhein-Westfalen, permit 84-02.04.2016.A531) and were performed in accordance with national animal protection guidelines.

\section{Consent for publication}

NA.

\section{Competing interests}

The authors declare that they have no competing interests.

\section{Author details}

${ }^{1}$ Institute-Associated Research Group "Cell adhesion and cell polarity", University of Münster, Von-Esmarch-Str. 56, 48149 Münster, Germany. ${ }^{2}$ Institute of Medical Biochemistry, ZMBE, University of Münster Von-Esmarch-Str. 56, 48149 Münster, Germany. ${ }^{3}$ Interdisciplinary Clinical Research Center (IZKF), University of Münster, Von-Esmarch-Str. 56, 48149 Münster, Germany. ${ }^{4}$ Department of Medicine D, Division of General Interna Medicine, Nephrology and Rheumatology, University Hospital of Münster, 48149 Münster, Germany. ${ }^{5}$ Laboratory for Cell Polarity and Organogenesis, Max-Planck-Institute for Heart and Lung Research, 61231 Bad Nauheim, Germany. ${ }^{6}$ Cells-in-Motion Cluster of Excellence (EXC 1003 - CiM), University of Münster, 48419 Münster, Germany.

Received: 11 December 2019 Accepted: 6 April 2020

Published online: 17 April 2020

\section{References}

1. Gumbiner BM. Regulation of cadherin-mediated adhesion in morphogenesis. Nat Rev Mol Cell Biol. 2005;6(8):622-34.

2. Williams AF, Barclay AN. The immunoglobulin superfamily--domains for cell surface recognition. Annu Rev Immunol. 1988;6:381-405.

3. Pawson T, Nash P. Assembly of cell regulatory systems through protein interaction domains. Science. 2003;300(5618):445-52.

4. Teyra J, Sidhu SS, Kim PM. Elucidation of the binding preferences of peptide recognition modules: SH3 and PDZ domains. FEBS Lett. 2012;586(17):26317. https://doi.org/10.1016/j.febslet.2012.05.043

5. Ernst A, Appleton BA, Ivarsson Y, Zhang Y, Gfeller D, Wiesmann C, Sidhu SS. A structural portrait of the PDZ domain family. J Mol Biol. 2014;426(21): 3509-19. https://doi.org/10.1016/j.jmb.2014.08.012.

6. Ebnet K, Suzuki A, Ohno S, Vestweber D. Junctional adhesion molecules (JAMs): more molecules with dual functions? J Cell Sci. 2004:117(1):19-29.

7. Songyang Z, Fanning AS, Fu C, Xu J, Marfatia SM, Chisti AH, Crompton A, Chan AC, Anderson JM, Cantley LC. Recognition of unique carboxy-terminal motifs by distinct PDZ domains. Science. 1997;275:73-7.

8. Meyer RD, Zou X, Ali M, Ersoy E, Bondzie PA, Lavaei M, Alexandrov I, Henderson J, Rahimi N. TMIGD1 acts as a tumor suppressor through regulation of p21Cip1/p27Kip1 in renal cancer. Oncotarget. 2018;9(11):967284. https://doi.org/10.18632/oncotarget.23822

9. Cattaneo E, Laczko E, Buffoli F, Zorzi F, Bianco MA, Menigatti M, Bartosova Z, Haider R, Helmchen B, Sabates-Bellver J, Tiwari A, Jiricny J, Marra G. Preinvasive colorectal lesion transcriptomes correlate with endoscopic morphology (polypoid vs. nonpolypoid). EMBO Mol Med. 2011:3(6):334-47.

10. Mojica W, Hawthorn L. Normal colon epithelium: a dataset for the analysis of gene expression and alternative splicing events in colon disease. BMC Genomics. 2010;11:5. https://doi.org/10.1186/1471-2164-11-5.

11. Roberts $\mathrm{DL}$, O'Dwyer ST, Stern PL, Renehan AG. Global gene expression in pseudomyxoma peritonei, with parallel development of two immortalized cell lines. Oncotarget. 2015;10:10786-800.

12. Lee J, Park EJ, Yuki Y, Ahmad S, Mizuguchi K, Ishii KJ, Shimaoka M, Kiyono H. Profiles of microRNA networks in intestinal epithelial cells in a mouse model of colitis. Sci Rep. 2015;5:18174. https://doi.org/10.1038/srep18174.

13. Lee J, Park EJ, Kiyono H. MicroRNA-orchestrated pathophysiologic control in gut homeostasis and inflammation. BMB Rep. 2016;49(5):263-9. https://doi. org/10.5483/bmbrep.2016.49.5.041.

14. Arafa E, Bondzie PA, Rezazadeh K, Meyer RD, Hartsough E, Henderson JM, Schwartz JH, Chitalia V, Rahimi N. TMIGD1 is a novel adhesion molecule that protects epithelial cells from oxidative cell injury. Am J Pathol. 2015;185(10): 2757-67. https://doi.org/10.1016/j.ajpath.2015.06.006.

15. Spinelli JB, Haigis MC. The multifaceted contributions of mitochondria to cellular metabolism. Nat Cell Biol. 2018;20(7):745-54. https://doi.org/10.1038/ s41556-018-0124-1.

16. Nemoto Y, De Camilli P. Recruitment of an alternatively spliced form of synaptojanin 2 to mitochondria by the interaction with the PDZ domain of a mitochondrial outer membrane protein. EMBO J. 1999;18(11):2991-3006. https://doi.org/10.1093/emboj/18.11.2991. 
17. Itakura E, Zavodszky E, Shao S, Wohlever ML, Keenan RJ, Hegde RS. Ubiquilins chaperone and triage mitochondrial membrane proteins for degradation. Mol Cell. 2016;63(1):21-33. https://doi.org/10.1016/j.molcel. 2016.05.020.

18. Matsuzaki T, Hanai S, Kishi H, Liu Z, Bao Y, Kikuchi A, Tsuchida K, Sugino H. Regulation of endocytosis of activin type II receptors by a novel PDZ protein through Ral/Ral-binding protein 1-dependent pathway. J Biol Chem. 2002;277(21):19008-18. https://doi.org/10.1074/jbc. M112472200.

19. Adam MG, Berger C, Feldner A, Yang WJ, Wustehube-Lausch J, Herberich SE, Pinder M, Gesierich S, Hammes HP, Augustin HG, Fischer A. Synaptojanin-2 binding protein stabilizes the notch ligands DLL1 and DLL4 and inhibits sprouting angiogenesis. Circ Res. 2013;113(11):1206-18. https://doi.org/10. 1161/CIRCRESAHA.113.301686.

20. Wang M, Wu H, Li S, Xu Z, Li X, Yang Y, Li B, Li Y, Guo J, Chen H. SYNJ2BP promotes the degradation of PTEN through the lysosome-pathway and enhances breast tumor metastasis via PI3K/AKT/SNAI1 signaling. Oncotarget. 2017;8(52):89692-706. https://doi.org/10.18632/oncotarget.21058.

21. Herzlinger DA, Easton TG, Ojakian GK. The MDCK epithelial cell line expresses a cell surface antigen of the kidney distal tubule. J Cell Biol. 1982; 93(2):269-77. https://doi.org/10.1083/jcb.93.2.269.

22. Rehder D, Iden S, Nasdala I, Wegener J, Brickwedde MK, Vestweber D, Ebnet K. Junctional adhesion molecule-a participates in the formation of apico-basal polarity through different domains. Exp Cell Res. 2006;312(17):3389-403.

23. Ebnet K. Junctional adhesion molecules (JAMs): cell adhesion receptors with pleiotropic functions in cell physiology and development. Physiol Rev. 2017; 97(4):1529-54. https://doi.org/10.1152/physrev.00004.2017.

24. Sato K, Otsu W, Otsuka Y, Inaba M. Modulatory roles of NHERF1 and NHERF2 in cell surface expression of the glutamate transporter GLAST. Biochem Biophys Res Commun. 2013;430(2):839-45. https://doi.org/10.1016/j.bbrc. 2012.11.059.

25. Engel U, Breborowicz D, Bog-Hansen T, Francis D. Lectin staining of renal tubules in normal kidney. Apmis. 1997;105(1):31-4. https://doi.org/10.1111/j. 1699-0463.1997.tb00536.x.

26. Varki A. Biological roles of glycans. Glycobiology. 2017;27(1):3-49. https://doi. org/10.1093/glycob/cww086.

27. Ryan MJ, Johnson G, Kirk J, Fuerstenberg SM, Zager RA, Torok-Storb B. HK-2: an immortalized proximal tubule epithelial cell line from normal adult human kidney. Kidney Int. 1994;45(1):48-57. https://doi.org/10.1038/ki.1994.6.

28. Vojtek AB, Hollenberg SM, Cooper JA. Mammalian Ras interacts directly with the serine/threonine kinase Raf. Cell. 1993;74(1):205-14.

29. Hollenberg SM, Sternglanz R, Cheng PF, Weintraub H. Identification of a new family of tissue-specific basic helix-loop- helix proteins with a twohybrid system. Mol Cell Biol. 1995;15(7):3813-22.

30. Liu ZH, Tsuchida K, Matsuzaki T, Bao YL, Kurisaki A, Sugino H. Characterization of isoforms of activin receptor-interacting protein 2 that augment activin signaling. J Endocrinol. 2006;189(2):409-21. https://doi.org/ 10.1677/joe.1.06420

31. Wong HS, Dighe PA, Mezera V, Monternier PA, Brand MD. Production of superoxide and hydrogen peroxide from specific mitochondrial sites under different bioenergetic conditions. J Biol Chem. 2017;292(41):16804-9. https://doi.org/10.1074/jbc. R117.789271

32. Che R, Yuan Y, Huang S, Zhang A. Mitochondrial dysfunction in the pathophysiology of renal diseases. Am J Physiol Renal Physiol. 2014;306(4): F367-78. https://doi.org/10.1152/ajprenal.00571.2013.

33. Daenen $K$, Andries A, Mekahli D, Van Schepdael A, Jouret F, Bammens B. Oxidative stress in chronic kidney disease. Pediatr Nephrol. 2019;34(6):97591. https://doi.org/10.1007/s00467-018-4005-4.

34. Pfanner N, Warscheid B, Wiedemann N. Mitochondrial proteins: from biogenesis to functional networks. Nat Rev Mol Cell Biol. 2019;20(5):267-84. https://doi.org/10.1038/s41580-018-0092-0.

35. Demory ML, Boerner JL, Davidson R, Faust W, Miyake T, Lee I, Huttemann M, Douglas R, Haddad G, Parsons SJ. Epidermal growth factor receptor translocation to the mitochondria: regulation and effect. J Biol Chem. 2009; 284(52):36592-604. https://doi.org/10.1074/jbc. M109.000760.

36. Cao X, Zhu H, Ali-Osman F, Lo HW. EGFR and EGFRvIll undergo stress- and EGFR kinase inhibitor-induced mitochondrial translocalization: a potential mechanism of EGFR-driven antagonism of apoptosis. Mol Cancer. 2011;10: 26. https://doi.org/10.1186/1476-4598-10-26.

37. Lee TY, Muschal S, Pravda EA, Folkman J, Abdollahi A, Javaherian K. Angiostatin regulates the expression of antiangiogenic and proapoptotic pathways via targeted inhibition of mitochondrial proteins. Blood. 2009; 114(9):1987-98. https://doi.org/10.1182/blood-2008-12-197236.

38. Chen M, Qiu T, Wu J, Yang Y, Wright GD, Wu M, Ge R. Extracellular antiangiogenic proteins augment an endosomal protein trafficking pathway to reach mitochondria and execute apoptosis in HUVECs. Cell Death Differ. 2018;25(11):1905-20. https://doi.org/10.1038/s41418-018-0092-9.

39. Hung V, Lam SS, Udeshi ND, Svinkina T, Guzman G, Mootha VK, Carr SA, Ting AY. Proteomic mapping of cytosol-facing outer mitochondrial and ER membranes in living human cells by proximity biotinylation. Elife. 2017;6. https://doi.org/10.7554/eLife.24463.

40. Meerbrey KL, Hu G, Kessler JD, Roarty K, Li MZ, Fang JE, Herschkowitz JI, Burrows AE, Ciccia A, Sun T, Schmitt EM, Bernardi RJ, Fu X, Bland CS, Cooper TA, Schiff R, Rosen JM, Westbrook TF, Elledge SJ. The pINDUCER lentiviral toolkit for inducible RNA interference in vitro and in vivo. Proc Natl Acad Sci U S A. 2011;108(9):3665-70. https://doi.org/10.1073/pnas.1019736108.

41. Keegan K, Cooper JA. Use of the two hybrid system to detect the association of the protein-tyrosine-phosphatase, SHPTP2, with another SH2containing protein, Grb7. Oncogene. 1996;12(7):1537-44.

42. Ebnet K, Schulz CU, Meyer Zu Brickwedde MK, Pendl GG, Vestweber D. Junctional adhesion molecule interacts with the PDZ domain-containing proteins AF-6 and ZO-1. J Biol Chem. 2000;275(36):27979-88. https://doi.org/ 10.1074/jbc. M002363200.

43. Evan Gl, Lewis GK, Ramsay G, Bishop JM. Isolation of monoclonal antibodies specific for human c-myc proto-oncogene product. Mol Cell Biol. 1985;5(12): 3610-6. https://doi.org/10.1128/mcb.5.12.3610.

44. Schiestl RH, Gietz RD. High efficiency transformation of intact yeast cells using single stranded nucleic acids as a carrier. Curr Genet. 1989;16(5-6): 339-46.

\section{Publisher's Note}

Springer Nature remains neutral with regard to jurisdictional claims in published maps and institutional affiliations.

Ready to submit your research? Choose BMC and benefit from:

- fast, convenient online submission

- thorough peer review by experienced researchers in your field

- rapid publication on acceptance

- support for research data, including large and complex data types

- gold Open Access which fosters wider collaboration and increased citations

- maximum visibility for your research: over $100 \mathrm{M}$ website views per year

At $\mathrm{BMC}$, research is always in progress.

Learn more biomedcentral.com/submissions 